\begin{tabular}{|c|c|}
\hline Title & $\begin{array}{l}\text { Continuous Daily Observation of the Marine A tmospheric Boundary Layer over the Kuroshio by a Helicopter Shuttle } \\
\text { Service }\end{array}$ \\
\hline Author(s) & Tanimoto, Y ouichi; Shimoyama, Kou; Mori, Shoichi \\
\hline Citation & $\begin{array}{l}\text { Journal of A tmospheric and Oceanic Technology, 32(1), 3-21 } \\
\text { https://doi.org/10.1175/JTECH-D-14-00067.1 }\end{array}$ \\
\hline Issue Date & $2015-01$ \\
\hline Doc URL & http:/hdl.handle.net/2115/57792 \\
\hline Rights & $\begin{array}{l}\text { (c) Copy right } 2015 \text { A merican Meteorological Society (A MS). Permission to use figures, tables, and brief excerpts from } \\
\text { this work in scientific and educational works is hereby granted provided that the source is acknowledged. A ny use of } \\
\text { material in this work that is determined to be " fair use" under Section } 107 \text { of the U.S. Copyright A ct or that satisfies } \\
\text { the conditions specified in Section } 108 \text { of the U.S. Copyright A ct (17 USC } \S 108 \text {, as revised by P.L. 94-553) does not } \\
\text { require the A MS' s permission. Republication, systematic reproduction, posting in electronic form, such as on a web } \\
\text { site or in a searchable database, or other uses of this material, except as exempted by the above statement, requires } \\
\text { written permission or a license from the A MS. A dditional details are provided in the A MS Copyright Policy, available } \\
\text { on the AMS W eb site located at (http://www.ametsoc.org/ or from the A MS at 617-227-2425 or } \\
\text { copyright@ ametsoc.org. }\end{array}$ \\
\hline Type & article \\
\hline File Information & jtech-d-14-00067.1-1.pdf \\
\hline
\end{tabular}

Instructions for use 


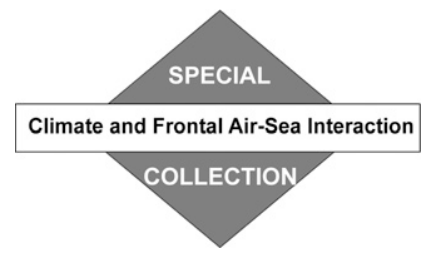

\title{
¿Continuous Daily Observation of the Marine Atmospheric Boundary Layer over the Kuroshio by a Helicopter Shuttle Service
}

\author{
YOUICHI TANIMOTO \\ Faculty of Environmental Earth Science, Graduate School of Environmental Science, Hokkaido University, Sapporo, Hokkaido, \\ and Research Institute for Global Change, JAMSTEC, Yokohama, Kanagawa, Japan \\ KOU SHIMOYAMA AND SHOICHI MORI \\ Institute of Low Temperature Science, Hokkaido University, Sapporo, Hokkaido, Japan
}

(Manuscript received 24 March 2014, in final form 16 September 2014)

\begin{abstract}
This paper describes a new initiative in which in situ observations of the marine atmospheric boundary layer (MABL) are made by a helicopter shuttle connecting six islands south of Tokyo. This observation method aims to make frequent measurements of temperature and moisture in the MABL across an ocean front, where direct measurements of the MABL have been limited. An onboard observation system to meet flight regulations was developed. Observed temperature and moisture as a function of pressure at 1-s intervals provided vertical profiles up to the $900-\mathrm{hPa}$ level above each of the islands, from 24 December 2010 to 6 April 2011, with the exception of an accidental power down in mid-February 2011. The observed values are validated by intercomparison with surface measurements from weather stations, atmospheric soundings, and mesoscale weather analysis provided by the Japan Meteorological Agency. Temperature and moisture values obtained using the system described here at the surface are significantly correlated with those from the weather station. The meridional changes revealed by the observed vertical profiles depict rich MABL structures, such as a cold-air intrusion and a strong near-surface inversion, that are not captured by the mesoscale weather analysis. However, this discrepancy is probably due to insufficient treatment in the mesoscale numerical model rather than observational errors. Additional intercomparisons indicate no influence from either artificial mixing by the helicopter rotor or by dynamic pressure caused by the fastmoving helicopter when obtaining the vertical profiles. Following these validations, the continuation of the initiative will allow for examining the influence of the ocean front on the overlying MABL on a synoptic time scale.
\end{abstract}

\section{Introduction}

Continuous and repeated in situ observations of the marine atmospheric boundary layer (MABL) along specific cross sections are very scarce over coastal regions and even rarer over the open oceans. Several previous studies, however, have conducted shipboard

\footnotetext{
๑ Denotes Open Access content.
}

Corresponding author address: Dr. Youichi Tanimoto, Faculty of Environmental Earth Science, Graduate School of Environmental Science, Hokkaido University, N10 W5, Kita-ku, Sapporo, Hokkaido 060-0810, Japan.

E-mail: tanimoto@ees.hokudai.ac.jp atmospheric soundings along a single cross section using a global positioning system (GPS) sonde. These studies have been successful in showing the distinct transition of temperature and moisture in the MABL across the steep front of sea surface temperature (SST) formed along western boundary currents, such as the Kuroshio and its extension (Tokinaga et al. 2006; Tanimoto et al. 2009; Tokinaga et al. 2009), the Gulf Stream (Sweet et al. 1981), and the Brazil-Malvinas Confluence region (Pezzi et al. 2005). While these observations have revealed the active effect of the SST front on the overlying MABL, our understanding of the ocean's role in affecting synoptic weather systems is still poor. This is because the limited number of soundings obtained during individual observation cruises does not allow 
the temporal changes of the MABL to be captured on a synoptic time scale. Instead, any synoptic weather disturbance occurring during the observation cruise has tended to be treated as noise when extracting the ocean-to-atmosphere effects.

Satellite measurements have the potential to provide frequent and global measurements of the vertical structures of temperature and moisture over the ocean. However, the vertical resolution of spaceborne instruments is quite low in the MABL, and the inversion procedures inherently involve uncertainty. Based on the assimilations of operational in situ and satellite measurements, operational weather analysis by the Japan Meteorological Agency (JMA) provides mesoscale $(\sim 15 \mathrm{~km})$ gridpoint values around Japan $\left(22.4^{\circ}-47.6^{\circ} \mathrm{N}\right.$, $\left.120^{\circ}-150^{\circ} \mathrm{E}\right)$. However, the products of these assimilations tend to be affected by problems in the way in which the numerical model represents the physics of the MABL (Song et al. 2009; Tanimoto et al. 2011).

In an effort to reduce these limitations in capturing the temporal variations of the MABL, we have developed an observation system for use on a helicopter shuttle to provide frequent sampling of the vertical temperature and moisture profiles in the MABL across the SST front along the Kuroshio. The Kuroshio flows predominantly eastward off the Pacific coast of Honshu, the largest Japanese island, before the Kuroshio Extension (KE) separates from the Japanese coast around $35^{\circ} \mathrm{N}, 141^{\circ} \mathrm{E}$, as indicated by $80-120-\mathrm{cm}$ contour lines in sea surface height ( $\mathrm{SSH}$; color shading in Fig. 1a), as seen in Archiving, Validation, and Interpretation of Satellite Oceanographic (AVISO) data. In addition, satellite measurements of SST (Kawamura et al. 2010) display a steep SST front, which is formed along the Kuroshio and KE (white contours in Fig. 1a). South of Tokyo, there are several small islands, known as the Izu Islands (Fig. 1b), that are mostly meridionally aligned near the main path of the Kuroshio. A helicopter shuttle service operates daily between those inhabited Izu Islands. Since the distances between the islands are $O(10-$ $100 \mathrm{~km}$ ), the cruising altitude of the regular shuttle flights does not exceed $1500 \mathrm{~m}$, which is close to the top of the MABL in this region. Cooperating with the air service company, we have begun a new initiative to measure temperature, moisture, and pressure during these flights. These measurements started on 24 December 2010 and were temporally halted on 6 April 2011 because of unavoidable complications following the 2011 TōhokuPacific Ocean earthquake and tsunami.

Along the path of the Kuroshio and KE, and their meanders, frontal structures and detached cold and warm eddies are displayed in the satellite snapshots of the SST field. These rich SST structures on the $O(100 \mathrm{~km})$ scale

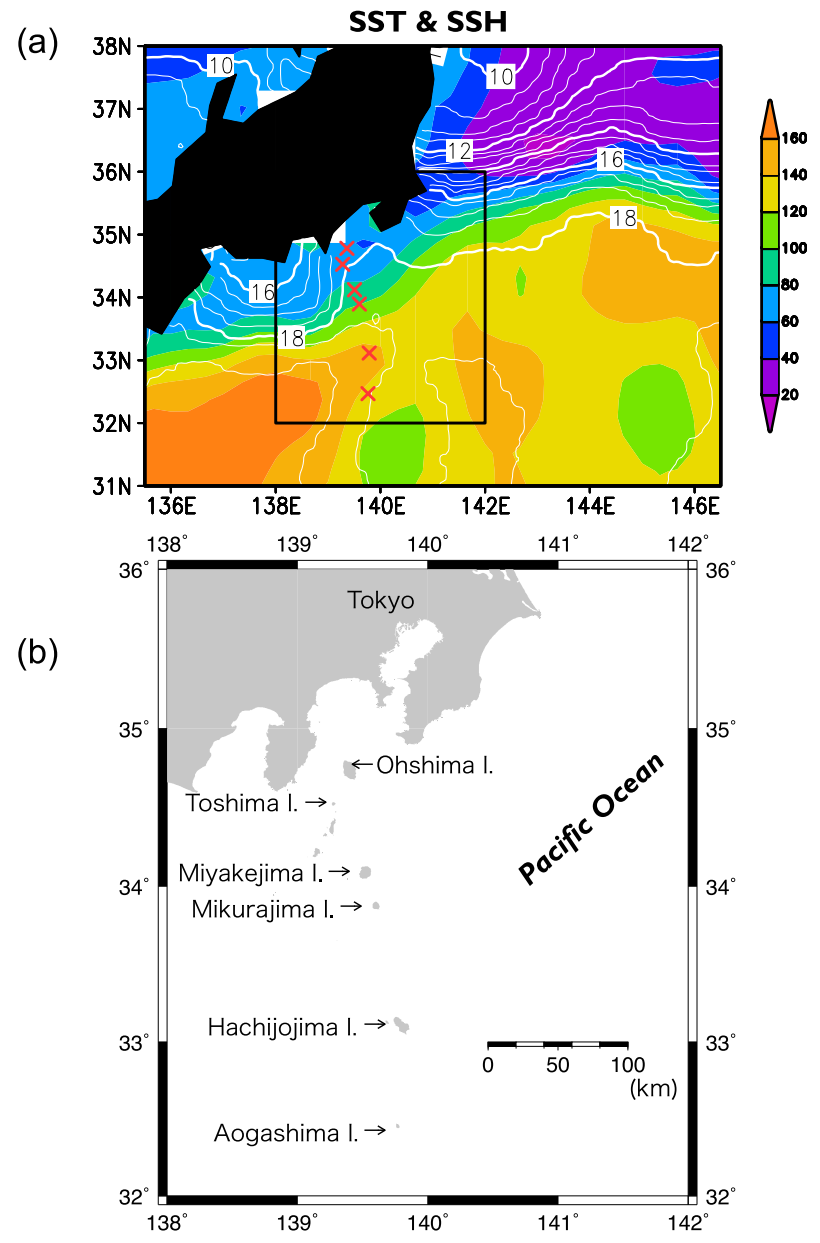

FIG. 1. (a) A snapshot of SSH (colors, cm) on 26 Jan 2011 and a 10-day mean of SST (white contours at $0.5^{\circ} \mathrm{C}$ intervals) averaged over 21-30 Jan 2011 off the Pacific Coast of Japan. SSH is provided by AVISO data, and SST is based on multiple satellite measurements by Kawamura et al. (2010). Coloring convention is shown on the right of the panel. The inset rectangle indicates the area showing (b) geographical locations of the six small Izu islands.

and the larger deformation scale in the atmosphere induce temperature and moisture disequilibrium near the sea surface, which then forms a region of intense heat release from the ocean surface (e.g., Figs. $3 \mathrm{c}$ and $3 \mathrm{~d}$ in Tanimoto et al. 2011). This feature of surface heat release produces pronounced atmospheric responses in the MABL structure, surface winds, cloud regime, sea level pressure (SLP), and precipitation, as reviewed by Kwon et al. (2010). Tanimoto et al. (2011) found that a wintertime ocean-atmosphere effect along the Kuroshio induces a westward-extending wedge of SLP minimum under the warm and mixed MABL because of hydrostatic adjustment (Lindzen and Nigam 1987), and associated westerly ageostrophic surface winds because of active vertical momentum mixing adjustment (Wallace et al. 1989; Hayes et al. 1989). While such adjustments in the 
TABLE 1. Locations, altitudes, and three-letter codes for each of the island airports (from the north). The three-letter codes used in this table and in the text are informal. While OIM, MYE, and HAC have formal International Air Transport Association three-letter codes, they are not used in the present study.

\begin{tabular}{lcccr}
\hline \hline Island name & Three-letter code & Lon & Lat & Alt (m) \\
\hline Ohshima & OIM & $139^{\circ} 21^{\prime} 37^{\prime \prime}$ & $34^{\circ} 46^{\prime} 55^{\prime \prime}$ & 38 \\
Toshima & TSM & $139^{\circ} 16^{\prime} 49^{\prime \prime}$ & $34^{\circ} 31^{\prime} 37^{\prime \prime}$ & 30 \\
Miyakejima & MYE & $139^{\circ} 30^{\prime} 22^{\prime \prime}$ & $34^{\circ} 07^{\prime} 19^{\prime \prime}$ & 56 \\
Mikurajima & MKR & $139^{\circ} 35^{\prime} 58^{\prime \prime}$ & $33^{\circ} 53^{\prime} 37^{\prime \prime}$ & 126 \\
Hachijojima & HAC & $139^{\circ} 47^{\prime} 09^{\prime \prime}$ & $33^{\circ} 06^{\prime} 54^{\prime \prime}$ & 92 \\
Aogashima & AOG & $139^{\circ} 45^{\prime} 47^{\prime \prime}$ & $32^{\circ} 28^{\prime} 10^{\prime \prime}$ & 274 \\
\hline
\end{tabular}

MABL were originally discussed with respect to changes in surface winds over the equatorial Pacific cold tongue, recent numerical studies have determined that the adjustments appear to be working in the extratropical frontal regions (see reviews of Small et al. 2008; Kwon et al. 2010). This MABL modulation by the SST front has the potential to influence regional weather and climate, not only over the Kuroshio but also along the Pacific coast of the Japanese islands, through changes in storm activity (Adachi and Kimura 2007; Iizuka 2010; Nakamura et al. 2012). The meridional section of the helicopter flights crosses the Kuroshio and the associated zonal low-SLP wedge, and hence offers a great opportunity to monitor the synoptic temporal variation of the MABL, as affected by the Kuroshio.

The remainder of this paper is organized as follows: Section 2 describes the observation system mounted on the helicopter and the datasets used for our validation work. Section 3 shows the preliminary results of the observations with intercomparisons with reference datasets. Section 4 presents a summary.

\section{Observation system and reference datasets}

\section{a. Tokyo Island Shuttle}

The Tokyo Island Shuttle (TIS) is a daily helicopter service operating between six Izu islands, connecting the gateway islands-Hachijojima, Miyakejima, and Ohshima-with regular jet flight services to and from Tokyo, with their neighboring small islands-Aogashima, Mikurajima, and Toshima. The shuttle is operated by Toho Air Service Co., Ltd. The locations and altitudes of each of the island airports are listed in Table 1 (also see Fig. 1b). For simplicity, the informal three-letter codes of the airports are employed in the present study. While the TIS service offers 10 regular flight legs a day, as shown in Table 2, it often provides supplemental flight legs for passengers and cargo. While the jet service between the gateway islands and Tokyo has been often canceled because of strong gusts over the gateway
TABLE 2. Timetable (JST) of the daily flight services of the TIS.

\begin{tabular}{ccccc}
\hline \hline Flight No. & Departs & \multicolumn{3}{c}{ Arrives } \\
\hline 11 & HAC & 0920 & AOG & 0940 \\
12 & AOG & 0945 & HAC & 1005 \\
21 & HAC & 1025 & MKR & 1050 \\
31 & MKR & 1055 & MYE & 1105 \\
51 & MYE & 1110 & OIM & 1130 \\
61 & OIM & 1150 & TSM & 1200 \\
62 & TSM & 1205 & OIM & 1215 \\
52 & OIM & 1455 & MYE & 1515 \\
32 & MYE & 1520 & MKR & 1530 \\
22 & MKR & 1535 & HAC & 1600 \\
\hline
\end{tabular}

airports, the TIS service is much less affected by windy conditions at the airports and operates with at least $95 \%$ success.

\section{b. Observation system}

The meteorological observation system was mounted on the body of the helicopter fleet (Fig. 2a; Sikorsky Aircraft Corporation S-76C+). Toho Air Service Co., Ltd. owns two fleets and operates the TIS with each fleet every 3 months. Since the fleet was not originally designed for making observations, the meteorological observations system must be compact, light, secure, stable, fireproof, and self-powered. It is also very important to note that neither the navigation system nor any other instruments installed on the helicopters are affected by our observational system. In addition to these limitations, the system should be mounted on the helicopters without any screwing or bolting to conform to flight regulations. To fulfill these requirements, we developed a new observational system suitable for the helicopter fleet instead of using a ready-made system.

The observation system consists of a sensor panel and a logging box (Fig. 3). The sensor panel $(9.5 \mathrm{~cm}$ wide, $5.8 \mathrm{~cm}$ long, and $1.0 \mathrm{~cm}$ thick), incorporating temperature and moisture sensors, is attached within a ventilation hole in the left-side door (port side) of the fleet (Fig. 2b). A logging box ( $27.5 \mathrm{~cm}$ wide, $12 \mathrm{~cm}$ long, and $12 \mathrm{~cm}$ high) with a pressure sensor is mounted in a pocket on the inner side of the left-side door (Fig. 2b). The total weight of the system is $2.0 \mathrm{~kg}$ and therefore treated as carry-on luggage in the cabin.

Because of the flight regulation that prohibits the edges of the sensors from being exposed on and outside the surface of the helicopter's body, the temperature and moisture measurement sensors are attached to the inner side of the ventilation hole on the left-side door (Fig. 2b), where ambient air outside the helicopter body directly flows in. After entering the ventilation hole, most of the airflow goes back out through another hole in the back side of the left-side door, while some passes 
(a)

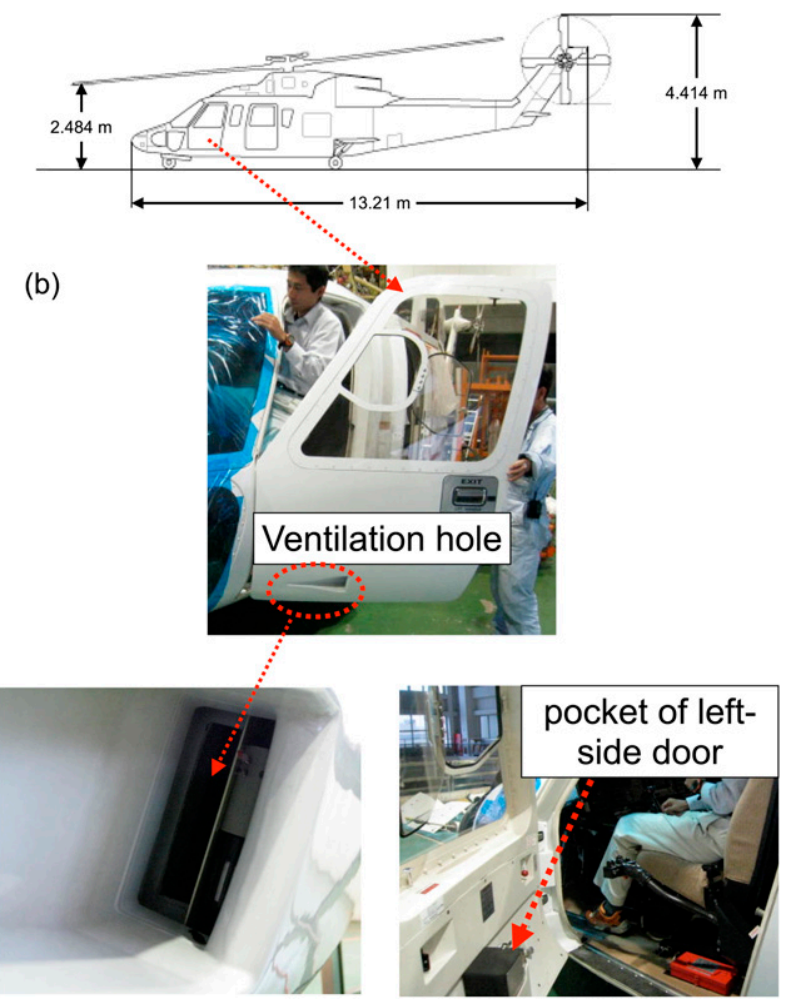

FIG. 2. (a) Body size of the helicopter fleet (Sikorsky Aircraft Corporation S-76C+). (b) (top) Ventilation hole (dashed red circle) on the left-side door of the fleet, (bottom left) a close-up view of the ventilation hole, (bottom right) logging box (at the point marked by dashed red arrow) mounted in the pocket on the inner side of the left-side door.

in the unpressurized cabin. Hence, our measurements of temperature, moisture, and pressure cannot be much affected by conditioned air from the cabin. Systematic errors due to the dynamic pressure of a high-speed helicopter will be examined in a later section by comparing vertical profiles with those from GPS sonde soundings on Hachijojima.

Ascent and descent speeds during takeoff and landing in the TIS operation are around $7.62\left(1500 \mathrm{ft} \mathrm{min}^{-1}\right)$ and $5.08 \mathrm{~m} \mathrm{~s}^{-1}\left(1000 \mathrm{ft} \min ^{-1}\right)$, respectively, under optimal conditions. To extract data with a vertical interval of $10 \mathrm{~m}$ or less, the sampling rate of measurements must be greater than $1 \mathrm{~Hz}$. To meet this sampling requirement, we employ the following highly responsive sensors: the self-made Chromel-Constantan thermocouples of 0.05and $0.08-\mathrm{mm}$ diameter for temperature, the Vaisala Inc. HUMICAP 180 for relative humidity, and the OMEGA Engineering Inc. PX2760-600A5V for pressure.

While the thinner thermocouple is at greater risk of being mechanically destroyed by the collisions of small particles than the thicker one, the temperature record of the former is less influenced by the radiation emitted from the helicopter body and the ambient air. In our observations, the records from the two types of thermocouple are compared.

The HUMICAP sensor is covered by a ventilation filter cap of $8-\mu \mathrm{m}$ thickness, preventing small particles from damaging or adhering to the sensor. Another thermocouple is installed in this filter cap for calculating the moisture mixing ratio. The response time of the filter-covered HUMICAP is approximately $10 \mathrm{~s}$ according to the data sheet provided by Vaisala Inc. When the filter cap was removed, the response time of the HUMICAP sensor was improved, to approach that of the desired sampling rate. However, we judged that the filter cap is necessary to protect against small particles while conducting 3 months of continuous operation.

The pressure sensor in this system has the advantages of having small dimensions $(57.1 \mathrm{~mm} \times 58.3 \mathrm{~mm} \times$ $27.2 \mathrm{~mm})$ and being lightweight $(\sim 100 \mathrm{~g})$, as well as having an instant warm-up through fast power excitation $(\sim 10 \mathrm{~ms})$. Although the power consumption of the pressure sensors tends to be large $(0.2 \mathrm{~W})$, the fast power excitation enables power saving in the system.

The logging device, CR1000-4M from Campbell Scientific, Inc., not only records the observations every second but also controls the power excitation to the sensors on a millisecond time scale. Consequently, the total power consumption was less than $0.08 \mathrm{~W}$ at $20^{\circ} \mathrm{C}$ in our laboratory testing of the system operation. This power-saving control enables us to conduct 3 months of continuous observation without maintenance. The power unit for the logging box has a total of $100 \mathrm{Wh}$ with 24 AAA-type nickel-metal hydride batteries. The logging device, pressure sensor, and power unit are contained within a custom-made aluminum box to eliminate electrical noise.

\section{c. Reference datasets}

For comparison with the measurements from our observation system, we use two datasets provided by the JMA. The first is the surface meteorological variables observed every $10 \mathrm{~min}$ by the Automated Meteorological Data Acquisition System (AMeDAS). The AMeDAS monitors surface temperature at the HAC airport (refer to Table 1 for acronym expansions) but does not measure pressure or relative humidity. Therefore, we use pressure and relative humidity data from an AMeDAS weather station on the same island, located $0.7 \mathrm{~km}$ away from the airport and at a higher altitude of $59 \mathrm{~m}$. Using these variables, the surface pressure at the HAC airport is estimated using the hydrostatic equation. The second dataset is the mesoscale operational weather analysis 


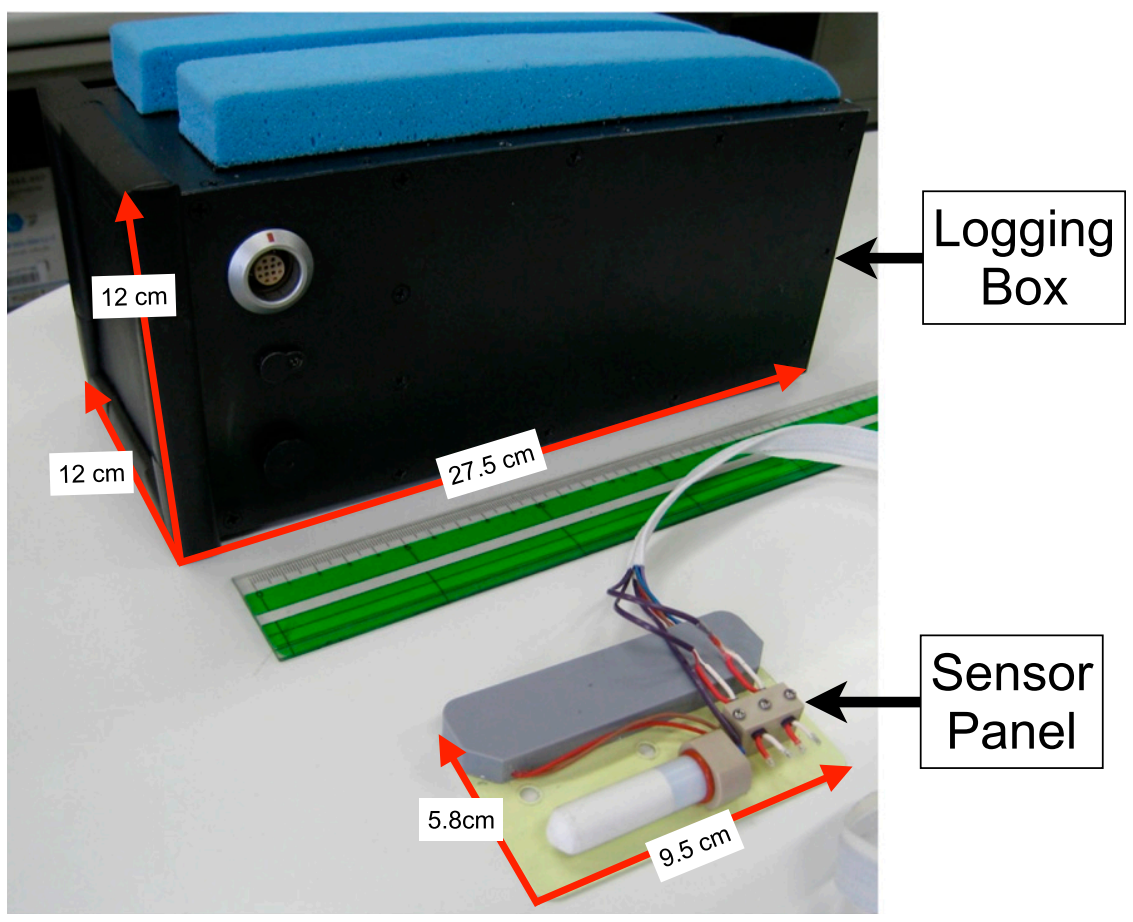

FIG. 3. Appearance and size of logging box and sensor panel.

(M-ANAL) for the Far East $\left(20^{\circ}-50^{\circ} \mathrm{N}, 120^{\circ}-150^{\circ} \mathrm{E}\right)$ produced by the JMA. This includes temperature, relative humidity, and geopotential height in the lower troposphere, available at 6-h intervals on a $0.20^{\circ}$ latitude $\times 0.25^{\circ}$ longitude grid. Note that the measurements from our observational system were not assimilated in the M-ANAL system.

\section{Preliminary results}

\section{a. Daily time series}

To examine the general features of the measurements made during the daily flight services, we show time series of pressure, temperature, and moisture mixing ratio on 25 December 2010 (day A) and 15 March 2011 (day B) in Figs. 4 and 5, respectively, as examples. Day A is the second day of the observation period. The JMA weather map on day A (Fig. 6a) shows low pressure centers at $50^{\circ} \mathrm{N}, 143^{\circ} \mathrm{E}$, and $155^{\circ} \mathrm{E}$, and a high pressure center at $49^{\circ} \mathrm{N}$ and $112^{\circ} \mathrm{E}$. In the southern portion of this synoptic weather system, a steep SLP gradient brings about surface northwesterlies or westerlies off the Pacific coast of Japan. Cold outbreaks into the warm ocean over the Kuroshio act to induce shallow cumuli along the surface isobars in our observation area, as shown in the satellite infrared (IR) image (Fig. 6c). On day B, we conducted GPS sonde soundings for the comparison of the vertical profiles. The JMA weather map on day B (Fig. 6b) shows weak low pressure centered at $32^{\circ} \mathrm{N}, 143^{\circ} \mathrm{E}$. While the center of this low is very close to our observation area, the SLP gradient off the Pacific coast of Japan is weaker on day B than on day A. The IR image (Fig. 6d) indicates clear-sky conditions in our observation area.

For temperature, the records from the $0.08-\mathrm{mm}$ thermocouple are used in this discussion because the records from the $0.05-\mathrm{mm}$ thermocouple became very noisy after mid-March 2011, apparently because of being damaged. The temperature records from the two thermocouples are almost identical in the first 2 months, indicating that the radiation from the fleet body had less effect on the 0.08-mm thermocouple than expected. In the present study, we employ Japan standard time (JST; UTC $+9 \mathrm{~h}$ ), which was used in the formal flight logbook originally written by the captain.

In the observed records from the TIS service, a rapid pressure decrease or increase implies that the helicopter is ascending or descending, respectively. Through comparison with the flight logbook, we determined that the beginning of the pressure decrease from the surface pressure and the end of the pressure increase to the surface pressure, around $1000 \mathrm{hPa}$, corresponded to the departure and arrival times, respectively. This correspondence is confirmed for all daily observations through 
(a)

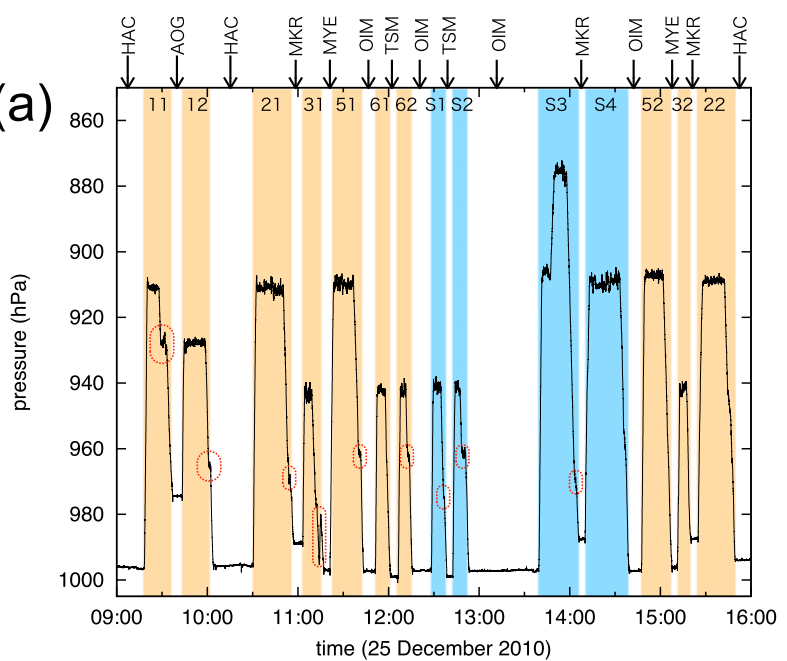

(b)

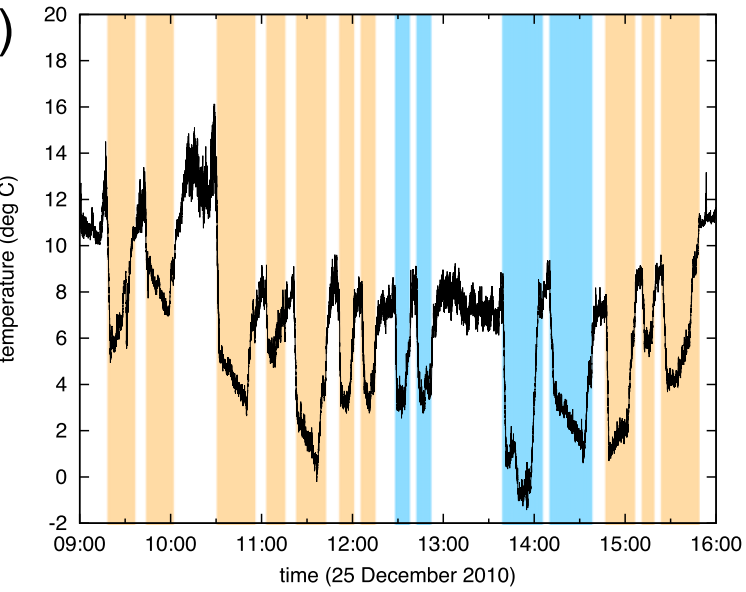

(c)

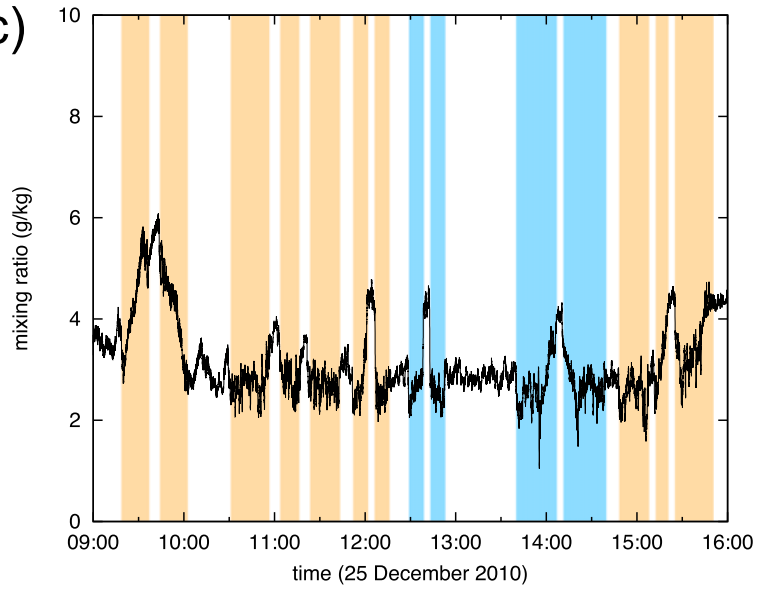

FIG. 4. Observed records of (a) pressure $(\mathrm{hPa})$, (b) temperature $\left({ }^{\circ} \mathrm{C}\right)$, and (c) moisture mixing ratio $\left(\mathrm{g} \mathrm{kg}^{-1}\right)$ on day A (25 Dec 2010). Orange and blue bands indicate the duration of the regular and supplemental flights, respectively. Flight numbers and airport names are given at the top of (a).

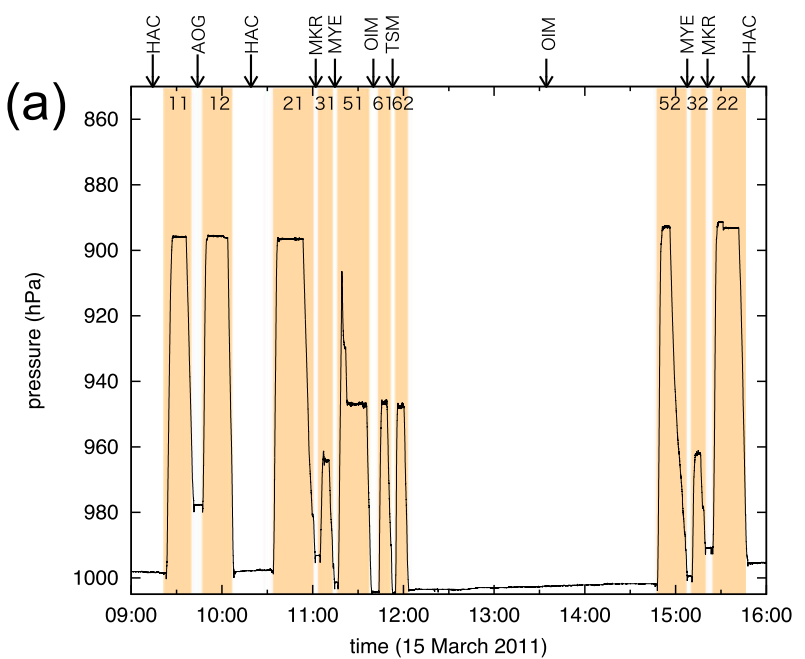

(b)

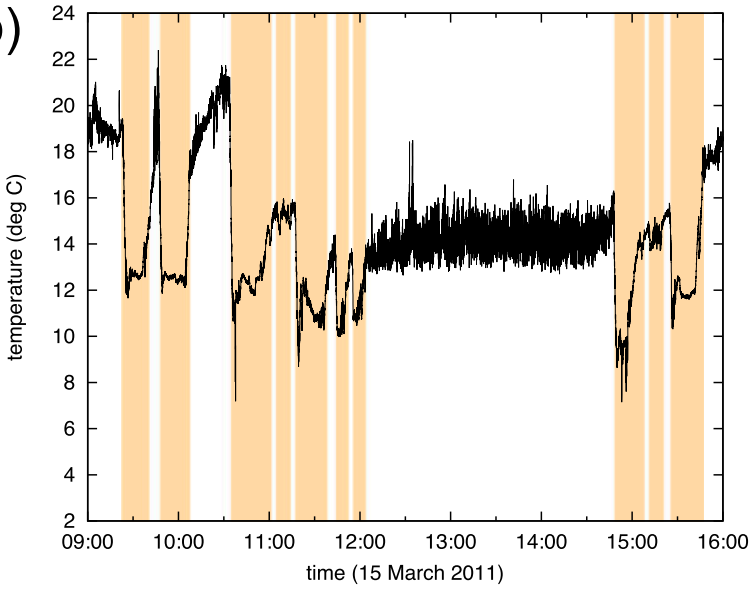

(c)

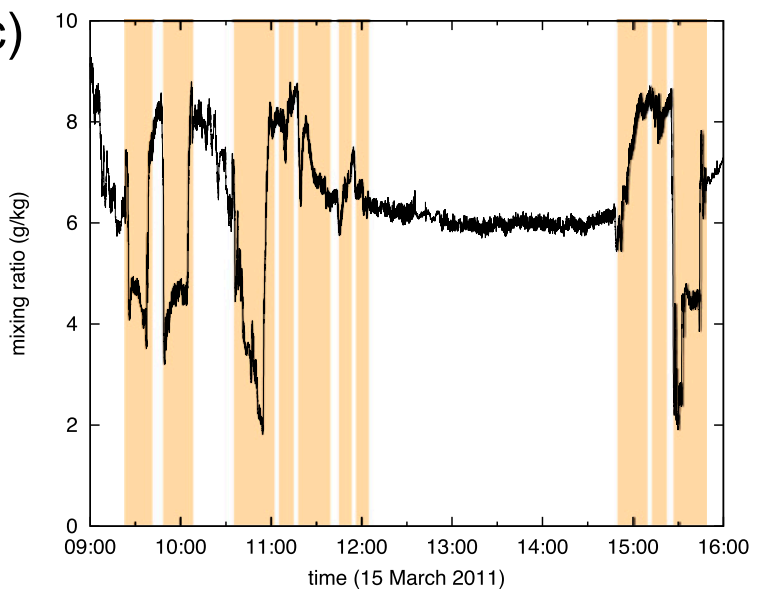

FIG. 5. As in Fig. 4, but on day B (15 Mar 2011).

the comparison of the pressure record and the flight logbook. Because of flight regulations, our observation system was not permitted to include a GPS system. Hence, the locations of departure and arrival are identified based only on the flight logbook. 
(a)

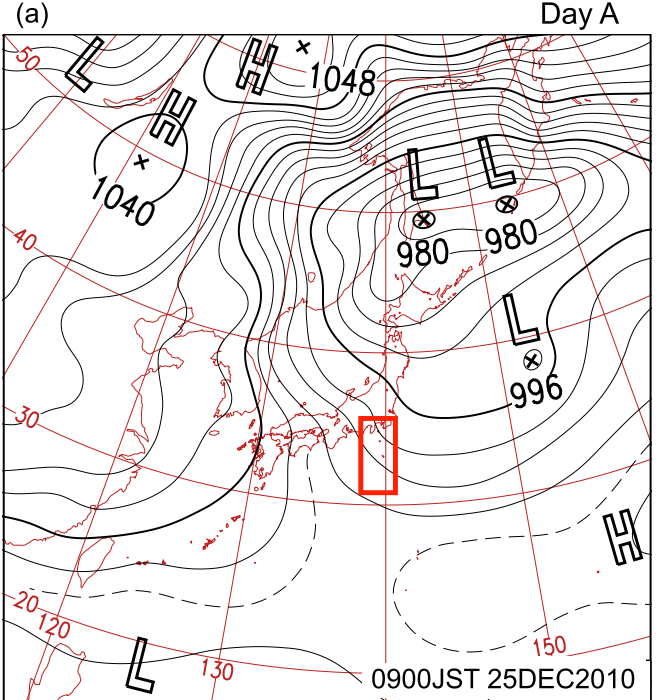

(c)

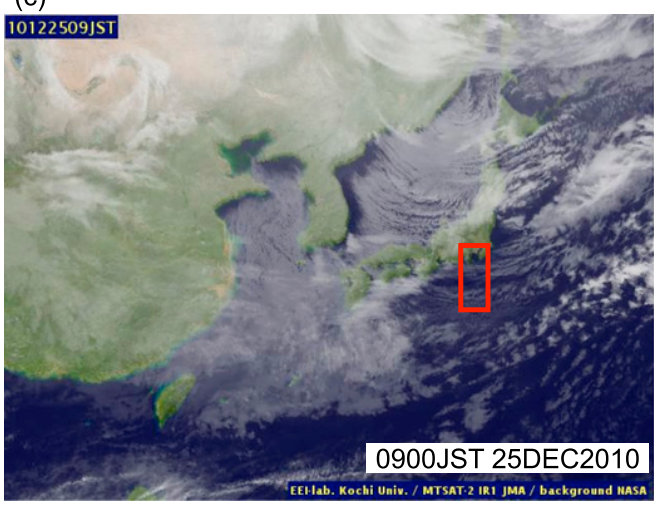

(b)

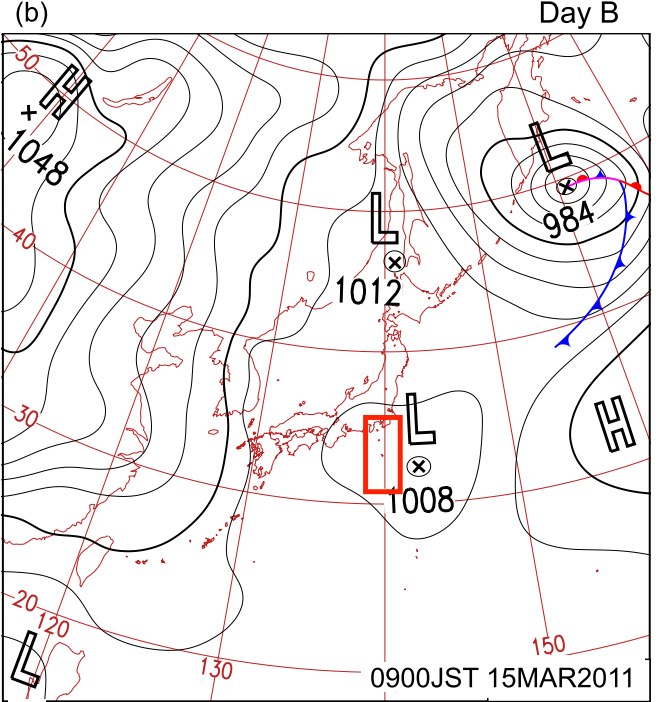

(d)

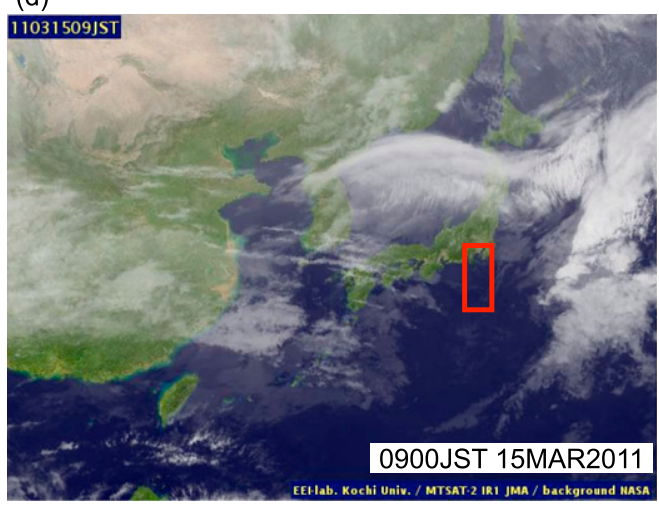

FIG. 6. JMA surface weather map for (a) 0900 JST 25 Dec 2010 (day A) and (b) 0900 JST 15 Mar 2011 (day B). The observation area is superimposed as a red rectangle. (c),(d) Corresponding infrared images from the Multifunctional Transport Satellite 2 (MTSAT-2) satellite. The satellite images are provided by Kochi University (http://weather. is.kochi-u.ac.jp/) and the JMA.

On day A, the pressure record indicates that 14 flight legs were operated from 0918 to 1550 JST, as represented by the orange and blue bands in Fig. 4. Correspondingly, as listed in Table 2, the flight logbook indicates 10 regular flight legs (orange bands in Fig. 4) and four supplemental flight legs (blue bands in Fig. 4). Note that the pressure records tend to be lower at the two island airports of MKR and AOG, because these airports are located at higher altitudes of more than $100 \mathrm{~m}$ above sea level (Table 1 ).

A few minutes after the rapid decrease of pressure during takeoff, pressure is mostly constant at a specific pressure level, indicating cruising at a certain altitude. As shown in Fig. 4a, the cruising altitude of each flight leg depends on its temporal duration between takeoff and landing. The specific pressure level of cruising is lower than $940 \mathrm{hPa}$ on longer flight legs, over $20 \mathrm{~min}$ (flights 11, 12, 21, 51, S3, S4, 52, and 22), but it is larger than $940 \mathrm{hPa}$ on shorter flight legs of around $10 \mathrm{~min}$ (flights 31, 61, 62, S1, S2, and 32).

Temperature records on day A (Fig. 4b) display rapid decreases while ascending after takeoff in each of the flight legs, suggesting that the vertical temperature profiles are successfully obtained near the island airports. In contrast, the temperature record while descending for landing contains spikelike fluctuations, rather than a gradual increase with a constant rate. This problem is discussed later in this section. We also note that temperature record displays nonnegligible fluctuations with amplitudes of around $\pm 1^{\circ} \mathrm{C}$ while parked on the apron at each of the airports, probably due to insufficient airflow through the ventilation hole.

The moisture mixing ratio (Fig. 4c) typically displays near-constant values of $3 \mathrm{~g} \mathrm{~kg}^{-1}$ with fluctuations of $0.5 \mathrm{~g} \mathrm{~kg}^{-1}$ during cruising in each of the flight legs. However, the observed mixing ratio shows several local 
maxima at the island airports, where it is $0.5-1.0 \mathrm{~g} \mathrm{~kg}^{-1}$ larger than during cruising. This indicates that the vertical change in moisture mixing ratio, with the temperature record but with more noise, is captured in the observed records, although the filter cap induces a slower response in moisture observation. At the OIM airport at around $1300 \mathrm{JST}$ on day A, the observed temperature was $7^{\circ}-8^{\circ} \mathrm{C}$ and the relative humidity was $45 \%$. Under these conditions, temperature fluctuations of $1^{\circ} \mathrm{C}$, such as those seen when parked on the apron, will induce moisture fluctuations of $0.20 \mathrm{~g} \mathrm{~kg}^{-1}$ or less; this is close to the observed moisture fluctuation.

In the northward flight legs 21 (from HAC to MKR) and 51 (from MYE to OIM) on day A, the cruising altitudes mostly remain at the 910 -hPa level. Temperature decreases by $2.4^{\circ} \mathrm{C}$ with nearly $0.78^{\circ}$ latitude $\left(3.1^{\circ} \mathrm{C}\right.$ per $1^{\circ}$ latitude), from $5.3^{\circ} \mathrm{C}$ at $1033 \mathrm{JST}$, at the 910 -hPa level above $\mathrm{HAC}$, to $2.9^{\circ} \mathrm{C}$ at $1050 \mathrm{JST}$ at the same level above MKR, and by $1.9^{\circ} \mathrm{C}$ with nearly $0.66^{\circ}$ latitude $\left(2.8^{\circ} \mathrm{C}\right.$ per $1^{\circ}$ latitude), from $2.5^{\circ} \mathrm{C}$ at $1123 \mathrm{JST}$ above MYE to $0.6^{\circ} \mathrm{C}$ at 1136 JST above OIM. A comparable amount of temperature decrease, $2.6^{\circ} \mathrm{C}$ per $1^{\circ}$ latitude, is also seen in the supplemental northward flight $\mathrm{S} 4$ from MKR to OIM, where the cruising altitude is close to the 910-hPa level. In the returning southward flights of 52 (from OIM to MYE) and 22 (from MKR to HAC), the cruising altitude is also at the $910-\mathrm{hPa}$ level. Temperature increase rates on each of the flight legs are $2.4^{\circ} \mathrm{C}$ per $1^{\circ}$ latitude for flight 52 and $1.8^{\circ} \mathrm{C}$ per $1^{\circ}$ latitude for flight 22 , which are nearly identical to the northward flights. Meridional change in moisture during these northward and southward cruisings is not as distinct as that seen in temperature. An exception to this is seen in the last leg, that of flight 22 , where we found the moisture mixing ratio to slightly increase southward. However, moisture changes in latitude and altitude are mixed in the recorded observations.

As stated in the previous paragraph, the observed records can show meridional changes in temperature and moisture. However, after our inspection of the daily pressure records, we found that the cruising altitude for the same flight leg changes slightly every day, probably due to the captain's best choice of navigating altitude. Given the vertical gradient in temperature and moisture, a slight change in cruising altitude can induce aliased daily fluctuations in the observed record. This means that these daily changes in cruising altitude render us incapable of capturing the daily variations in horizontal profiles of the observed variables at a certain pressure level.

As stated in section 2a, the ascending speed is faster than the descending speed. A closer look at the pressure record indicates that the pressure increases that occur
25 Dec. 2010

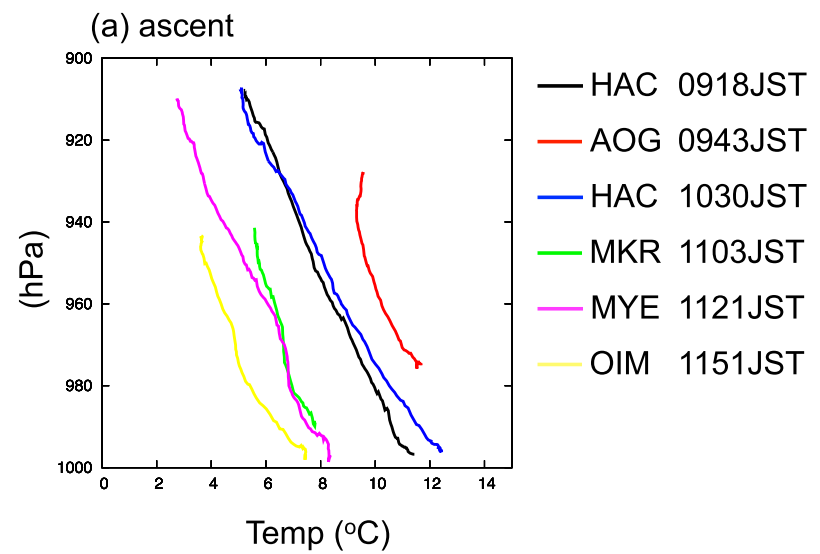

(b) descent

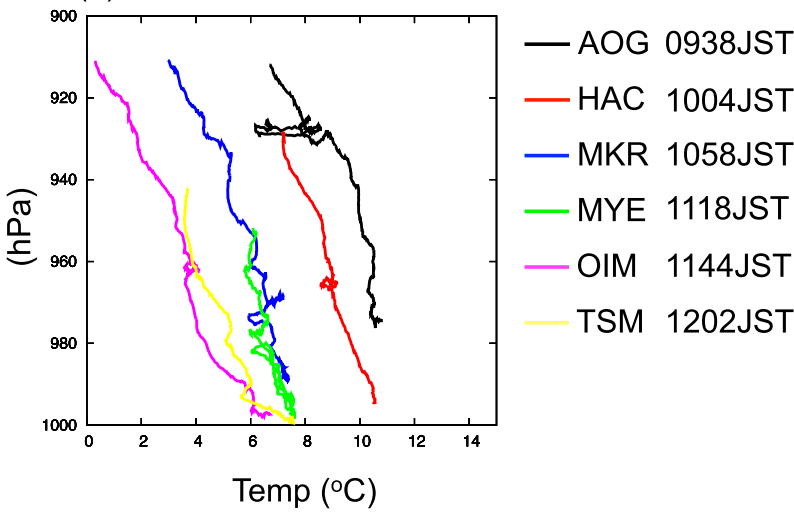

FIG. 7. Vertical temperature profiles $\left({ }^{\circ} \mathrm{C}\right)$ from TIS observation during (a) ascents and (b) descents based on the morning flight legs on day A. The observed time (JST) and the takeoff/landing airports are indicated on the right.

while descending are not as smooth as the pressure decreases while ascending. Small pressure fluctuations at certain pressure levels, marked by slight pressure increases, are found while descending, as marked by inset dashed red circles in Fig. 4a. These characteristic differences in the pressure changes while ascending and descending suggest that the vertical profiles of temperature and moisture are better captured in the observed record while ascending. Figure 7 displays several vertical profiles of temperature as a function of pressure in the morning flight legs on day A, during both ascents and descents. While smooth vertical profiles are obtained from the observed records during ascents, the profiles during descents are not as smooth. Thus, the observed records during descents are considered to include significant noise at several vertical levels in each of the profiles. Similar noise tends to be found in other profiles during descents, but not during ascents. An inspection of pressure records indicates that the helicopters tend to 


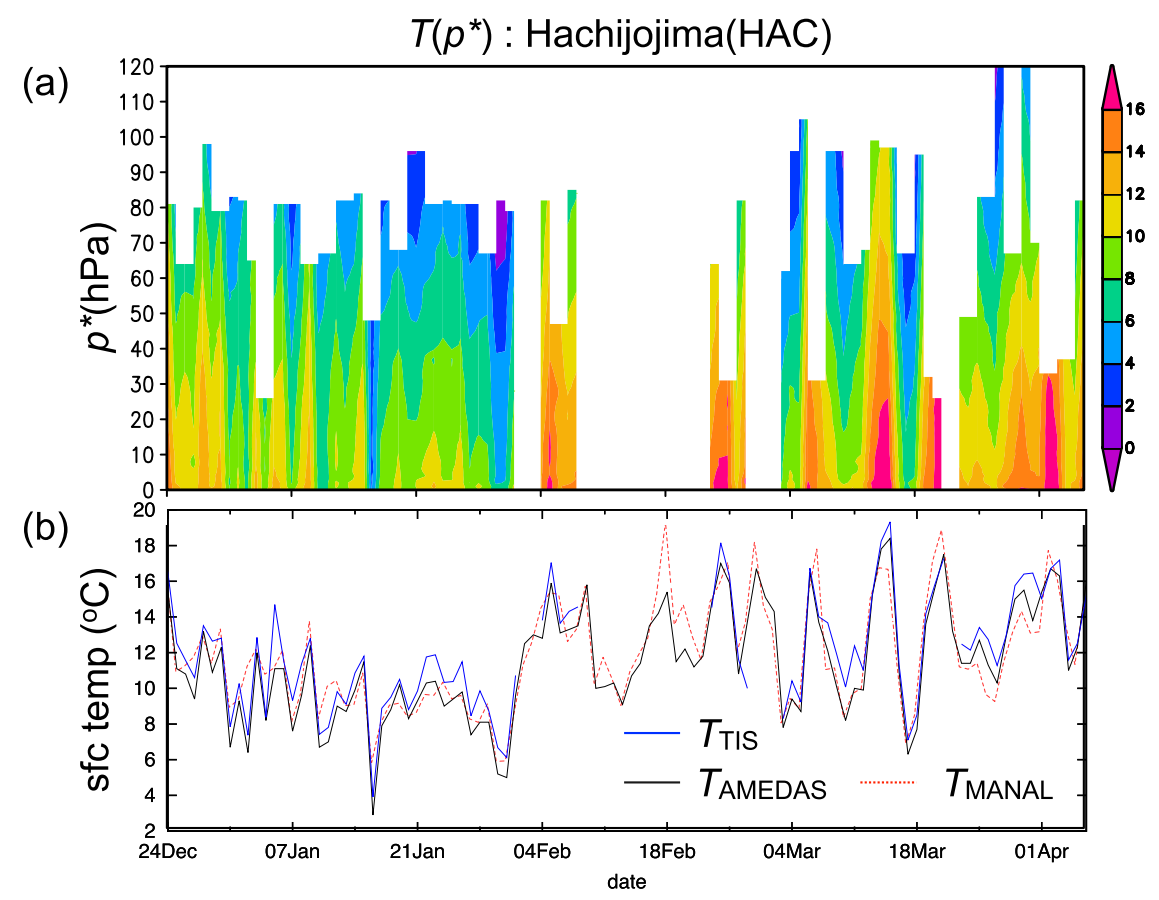

FIG. 8. (a) Time series of the observed vertical temperature profile $\left({ }^{\circ} \mathrm{C}\right)$ at $\mathrm{HAC}$ from $24 \mathrm{Dec}$ 2010 to 6 Apr 2011 as a function of $p^{*}(\mathrm{hPa})$. Coloring convention is represented to the right of the panel. (b) Time series of the observed surface temperature at HAC from the TIS (blue lines) and AMeDAS (black lines). Temperature time series at the $1000-\mathrm{hPa}$ level from M-ANAL data at the nearest grid point to HAC (dashed red lines).

remain at a certain level for a few dozen seconds before landing at the airports, probably for navigation reasons. Thus, the navigation during descent may cause some disruption to airflow over the sensors.

On day B, the pressure record (Fig. 5a) indicates that 10 regular flight legs were operated from 0923 to 1548 JST, as documented in the flight logbook. Temperature decreases during ascent, and accompanying decreases in pressure are well captured in all the flight legs, except during flights 31 and 32, where the cruising height was below the 960-hPa level between MKR and MYE (Fig. 5b). Moisture decreases during ascent are also seen on the longer flight legs over $20 \mathrm{~min}(11,12,21,51,52$, and 22) (Fig. 5c). In contrast to day A, the meridional temperature changes are indistinct, despite the cruising altitude being mostly constant during those longer flight legs. However, as found on day A, temperature and moisture fluctuations while parked at each of the airports also tend to be large on day B, especially at OIM. Hereafter, we will examine the records collected only during ascent but not during cruising, descent, or while parked.

\section{b. Observed vertical profiles}

The measurements made at a frequency of $1 \mathrm{~Hz}$ during ascent can be transformed into the profile as a function of pressure. Figure 8a shows the time series of the vertical temperature profile at HAC airport from 24 December 2010 to 6 April 2011 based on the measurements of pressure and temperature during the ascent of regular flight 21 to MKR, with a scheduled departure time of 1025 JST. To avoid changes due to the diurnal cycle, we only include those profiles observed between 1000 and 1100 JST. Note that the vertical axis in Fig. 8a is the pressure differential relative to the land surface $\left[p^{*}(\mathrm{hPa})\right]$ at the HAC airport, that is, $p^{*}=p-p_{\text {surface }}$ (e.g., Ninomiya 1977). Even during strong cold surges caused by the northwesterly East Asian monsoon, regular flight operation during our observation period was almost continuous, and thereby provides us with the opportunity for very frequent sampling of the vertical temperature profiles. While several data points are missing, spanning periods of 1-2 days because of flight cancellations, one longer period of omission, between 9 and 22 February 2011, was due to an unexpected power down of the observation system. For the discussion in this subsection, we use the temperature record from the thicker $0.08-\mathrm{mm}$ thermocouple because the record from the thinner one $(0.05 \mathrm{~mm})$ was found to have many missing data points, especially during the last month. We note that the differences in temperature recorded by the two 


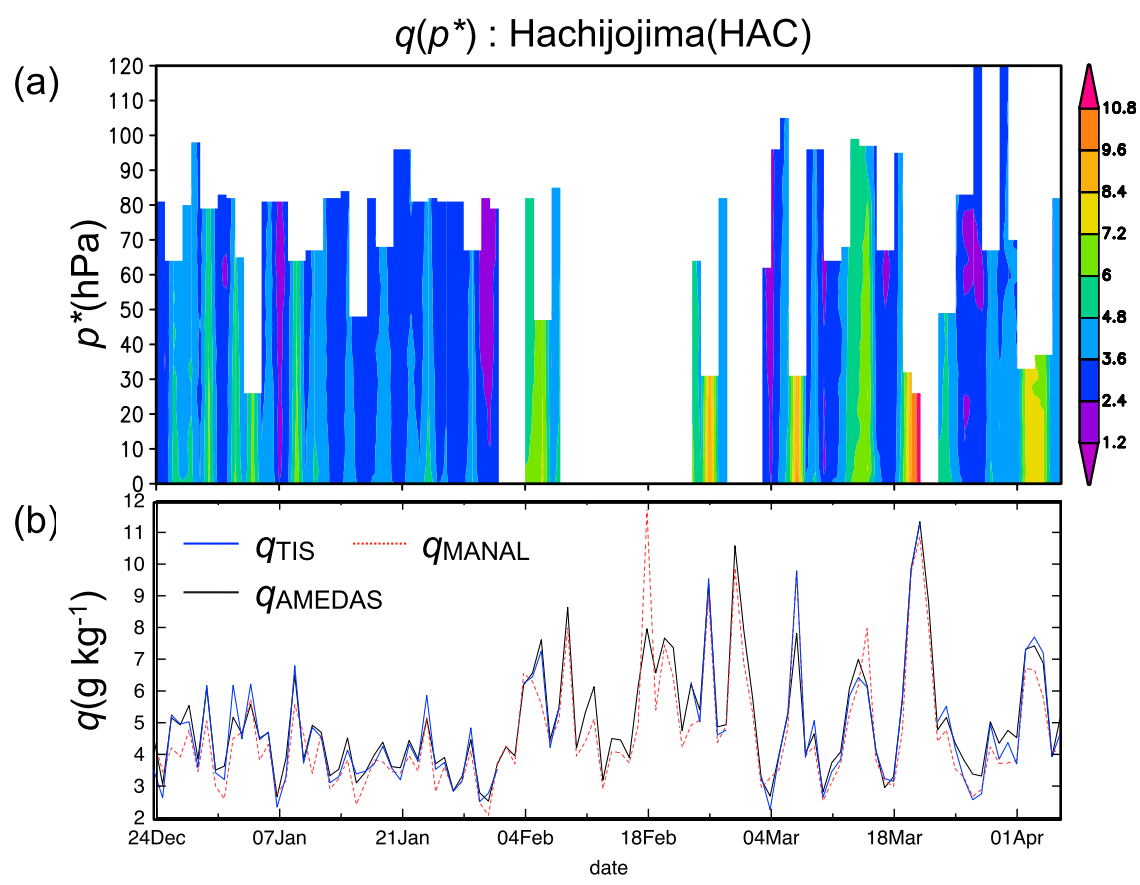

FIG. 9. As in Fig. 8, but for the moisture mixing ratio $\left(\mathrm{g} \mathrm{kg}^{-1}\right)$.

thermocouples were no greater than $0.15^{\circ} \mathrm{C}$ during the period that both of them worked together.

Most of the observed temperature profiles reached $70-80 \mathrm{hPa}$ in $p^{*}$, which corresponds to a height of around $700-800 \mathrm{~m}$. In the present study, the top of the vertical profiles is determined as the end of the ascent before cruising at a certain pressure level. The end of the ascent is found by the following procedure: 1) a 21-s running mean is applied to the original $1-\mathrm{Hz}$ pressure record after takeoff, 2) we count the number of $1-\mathrm{Hz}$ measurements over every 11-s running window when the pressure change on the running mean record is greater than $-0.2 \mathrm{hPa} \mathrm{s}^{-1}$, and 3) the end of the ascent is determined as the first time at which the counted number exceeds 7 in 10 after the takeoff. By the visual inspection of the pressure record, we determined that some flights had additional ascents after obtaining a cruising altitude for a few dozen seconds at the level of the defined top. While these additional ascents are often found when the top of the vertical profile is defined below $50 \mathrm{hPa}$ in $p^{*}$, the additional vertical profiles are not used here because we regarded them as being recorded at a location far from the takeoff airports.

The nearly 3-month observation of vertical temperature reveals synoptic fluctuations on the scale of a few days, as well as a gradual seasonal change in which the minimum temperature is observed during late January to early February. Figure 8 b shows two observed surface temperature time series at HAC airport, from our observation system on the TIS service (blue lines) and from the airport weather station of the AMeDAS (black lines), displaying the synoptic fluctuations superimposed over the seasonal change. Since the AMeDAS record is archived every $10 \mathrm{~min}$, we selected the AMeDAS data collected closest to the departure time of flight 21 each day. While a slight positive bias is found in our observation system relative to AMeDAS, both the time series are well correlated, with a simultaneous correlation coefficient of $r_{0}=0.98$. This shows that our observation system is able to accurately capture both synoptic scale and seasonal variability.

The time series of moisture mixing ratio from our observations (Fig. 9a) displays a weak vertical gradient in each of the daily vertical profiles. The slower response of the moisture measurement in our system may act to reduce vertical gradients in the observed record during ascent, with the maximum delay of $10 \mathrm{~s}$ in the moisture measurement inducing a systematic bias of around $80 \mathrm{~m}$ (approximately $8 \mathrm{hPa}$ in $p^{*}$ ) given the average speed of ascent $\left(7.62 \mathrm{~m} \mathrm{~s}^{-1}\right)$ of the TIS operations. The weak vertical gradients in Fig. 9a, however, are often found up to a level of $50 \mathrm{hPa}$ in $p^{*}$, indicating that vertical water vapor mixing is active, at least up to the top of the observed profiles. This vertically coherent moisture structure also shows the synoptic fluctuations seen in the temperature records. The surface moisture mixing ratio obtained by the TIS $\left(p^{*}=0\right)$ is significantly correlated with that recorded by AMeDAS and $r_{0}$ of 0.97 (Fig. 9b), 


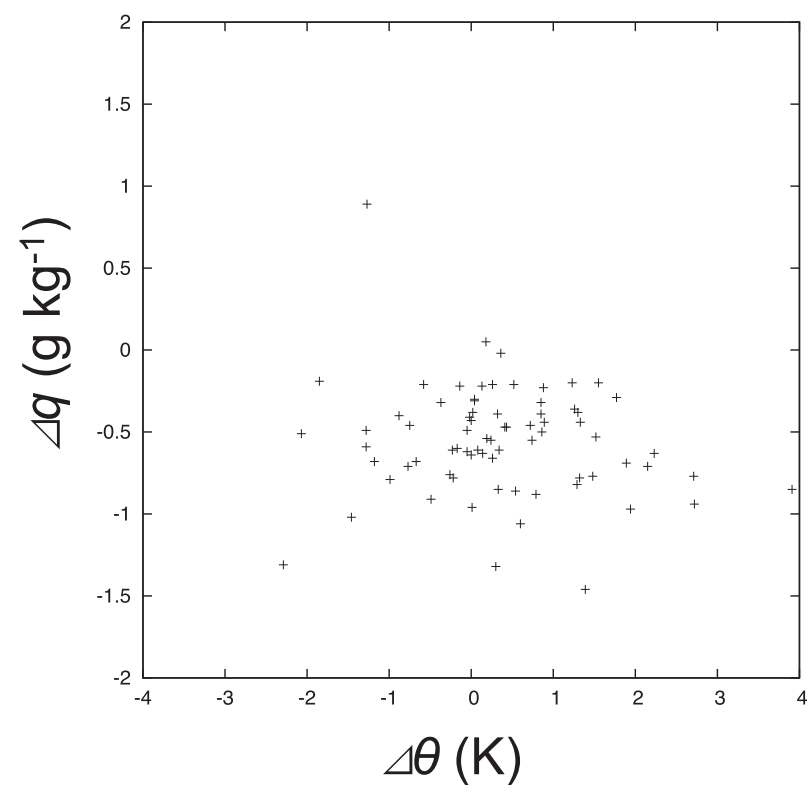

FIG. 10. Scatterplots of the vertical differences in potential temperature $(\Delta \theta, \mathrm{K})$ and moisture mixing ratio $\left(\Delta q, \mathrm{~g} \mathrm{~kg}^{-1}\right)$ between $50 \mathrm{hPa}$ in $p^{*}$ and the surface based on the TIS observations at HAC.

despite our previous concern that the ventilation filter cap enveloping the HUMICAP sensor might delay airflow in the sensor and thereby induce a bias in the moisture mixing ratio. Although pressure and relative humidity are monitored by the AMeDAS in a slightly different location and altitude from the HAC airport, as stated in section $2 \mathrm{c}$, the moisture mixing ratio provided by the TIS observations in the lower layer below $60 \mathrm{~m}$ is mostly identical and well correlated with the AMeDAS moisture mixing ratio.

An overall comparison of Figs. $8 \mathrm{~b}$ and $9 \mathrm{~b}$ indicates that the synoptic fluctuations in the near-surface moisture mixing ratio appear to mostly depend on the temperature fluctuations. As an example, the values observed on 7, 14 and 15, and 21 March 2011 show local maxima both in temperature and moisture mixing ratio. However, a closer examination of the surface records shows that the highest moisture mixing ratio among these three periods was on 21 March 2011, while temperature record shows a different relation between the 3 days. The differences in the synoptic fluctuations of moisture and temperature are also seen in the vertical profiles. As shown in Fig. 10, vertical differences in the moisture mixing ratio $(\Delta q)$ between $50 \mathrm{hPa}$ in $p^{*}$ and the surface are not well correlated with the vertical differences in potential temperature $(\Delta \theta)$, with an $r_{0}$ of only -0.13 . These results mean that our observations of relative humidity together with temperature are necessary to represent the actual conditions of the boundary layers, below which the air-sea heat and moisture exchanges are very active.

\section{c. Intercomparisons with mesoscale analysis data}

\section{1) TIME SERIES AT HAC AIRPORT}

In addition to the seasonal progression of temperature (Fig. 8), the static stability of the near-surface layer also shows a gradual seasonal change, from mostly stable in December-January to mostly unstable in March-April. Figure 11a shows a time series of vertical differences in potential temperature $(\Delta \theta)$ between $50 \mathrm{hPa}$ in $p^{*}$ and the surface (solid lines), and between $25 \mathrm{hPa}$ in $p^{*}$ and the surface (dashed lines). While synoptic fluctuations are dominant in these series, the two well-correlated time series of $\Delta \theta$ in the lower $500 \mathrm{~m}$ show the stable and unstable conditions of the lower MABL during the first and last 20 days of the observation period, respectively.

These characteristics of vertical stability in the nearsurface layers are rarely found in the M-ANAL data. While, as represented by dashed red lines in Fig. 8b, the temperature fluctuations at the $1000-\mathrm{hPa}$ level in the M-ANAL data at the nearest grid point to HAC aiport $\left(33^{\circ} 20^{\prime} \mathrm{N}, 133^{\circ} 25^{\prime} \mathrm{E}\right)$ are mostly similar to the measurements from the TIS service $\left(r_{0}=0.75\right)$ and AMeDAS $\left(r_{0}=0.79\right)$, the $\Delta \theta$ of the M-ANAL data between 1000 and $950 \mathrm{hPa}$ shows neutral stability for most of the time during our observation period (Fig. 11b). The same is true for the layer below $975 \mathrm{hPa}$.

The moisture mixing ratio at $1000 \mathrm{hPa}$ in the $\mathrm{M}$-ANAL data mostly reflects the synoptic fluctuations, as also observed in the TIS and AMeDAS data (Fig. 9b). The correlation coefficients of the M-ANAL data with the surface observations are statistically significant, that is, $r_{0}=0.94$ for TIS and 0.93 for AMeDAS, although the variance is slightly larger in the M-ANAL data than in the others. We note the fact that the exact location of the M-ANAL grid point is different from that of the HAC airport; however, we will not pursue the precise reason for the larger variance in the M-ANAL data. Therefore, although the nearsurface moisture mixing ratios at the nearest grid point of the M-ANAL data tend to follow the observed records from the TIS service and AMeDAS, the vertical structure of the moisture mixing ratio in the M-ANAL data is unlikely to match the TIS observations due to inconsistencies in potential temperature, as shown in Fig. 11.

This intercomparison between in situ TIS observations and the mesoscale weather analysis suggests that the treatment of the planetary boundary layer is inadequate in the M-ANAL system, rather than suggesting that our observation system provides inaccurate vertical profiles. Future continuous observations by the helicopter shuttle potentially provide important in situ 
(a)

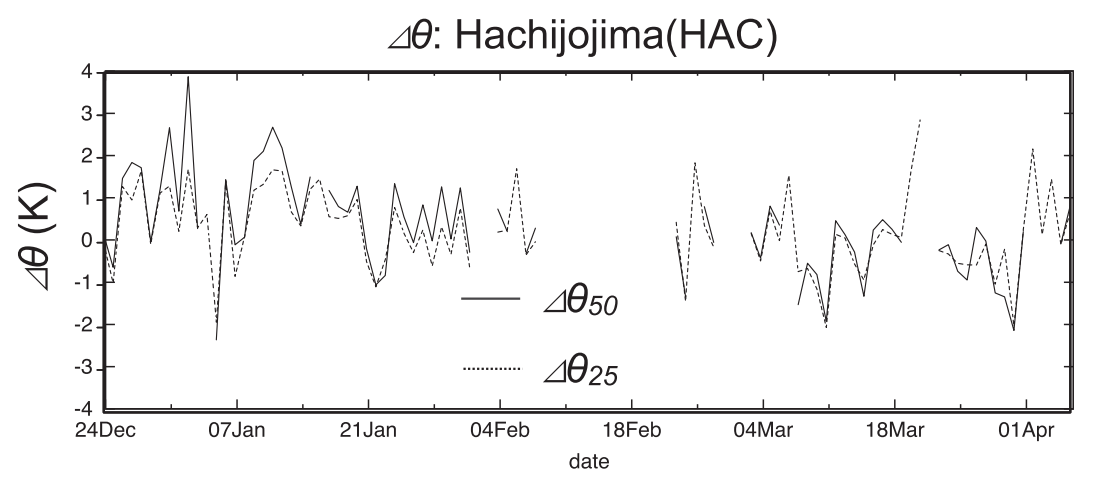

(b)

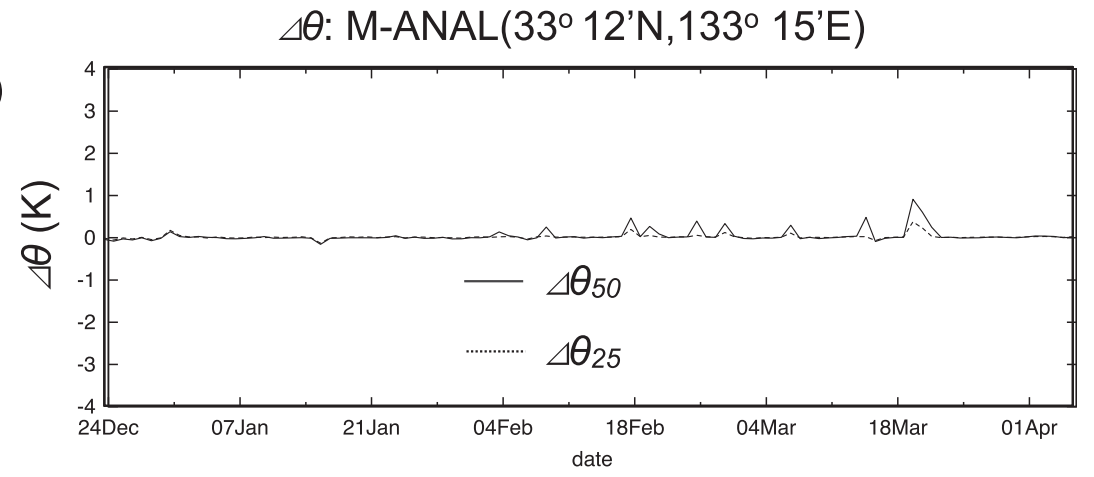

FIG. 11. (a) Time series of the vertical differences in potential temperature $(\Delta \theta, \mathrm{K})$ between $50 \mathrm{hPa}$ in $p^{*}$ and the surface (solid lines) and between $25 \mathrm{hPa}$ in $p^{*}$ and the surface (dashed lines) based on the TIS observations at HAC. Positive and negative values of $\Delta \theta$ indicate stable and unstable conditions in the MABL, respectively. (b) As in (a), but based on M-ANAL data.

data to contribute to improvements in how the vertical structures of the MABL are represented in the M-ANAL system, as well as in regional atmospheric numerical models.

\section{2) Meridional Sections}

Our new observation system has proved mostly successful in providing the vertical profiles of temperature and moisture at each of the island airports, as displayed for the HAC airport in Figs. 8a and 9a. This enables us to obtain daily meridional sections spanning $32.4^{\circ}-34.8^{\circ} \mathrm{N}$, based on the vertical profiles from AOG to OIM, because the islands are more-or-less aligned meridionally in the $0.5^{\circ}$ zonal band of $139^{\circ} 16^{\prime}-48^{\prime} \mathrm{E}$, as stated in section 1 . For the discussion of the meridional sections presented in this subsection, we employ only those vertical profiles obtained during ascents in the morning flight legs, with respect to local time, at each of the airports, corresponding to flight 12 at AOG, flight 21 at HAC, flight 31 at MKR, flight 51 at MYE, flight 61 at OIM, and flight 62 at TSM (Table 2).

Figures 12 and 13 illustrate the meridional cross sections of potential temperature $(\theta)$ as a function of pressure level, as observed by the TIS service on day A and day B, respectively. Based on the M-ANAL data, we also made virtual cross sections (Figs. 12b and 13b) and conventional single cross sections (Figs. 12c and 13c). For the virtual cross section, we collected six vertical profiles from the 3-h M-ANAL data, from the grid point and time nearest to those of our observed profiles, for each of the airports. For the single cross section, we used only values along $139^{\circ} 45^{\prime} \mathrm{E}$ at $0900 \mathrm{JST}$ (0000 UTC) because the observations for the daily cross sections were completed within $3 \mathrm{~h}$ of this time. For example, in the selected instances illustrated in Figs. 12a and 13a, the observed profiles are obtained between 0943 JST at AOG and 1205 JST at TSM on day A, and between 0947 JST at AOG and 1154 JST at TSM on day B. We note that the M-ANAL sections mostly display the same MABL structure in the meridional cross sections, either along neighboring longitudes at the same time or along those longitudes at the next assimilated time step at 1200 JST. We also point out that a linear interpolation of the $\theta$ values between the airports is performed in the lateral direction but not vertically in the observed cross section. The airport locations are indicated by open triangles in the horizontal axis of each panel.

While the observed cross section on day A (Fig. 12a) is based on the profiles in the limited layer between the 930- and 980-hPa levels, with coarse meridional 


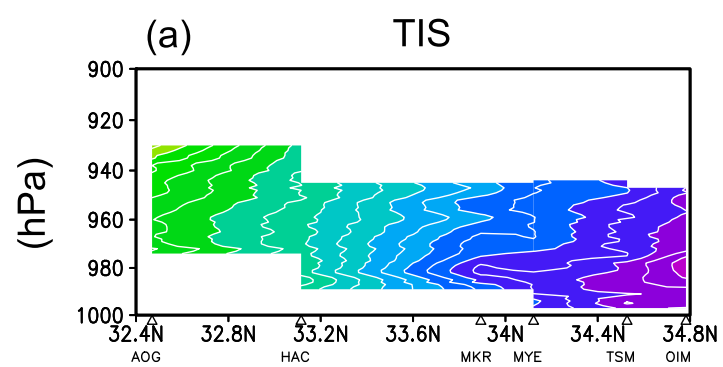

(b) M-ANAL(virtual section)

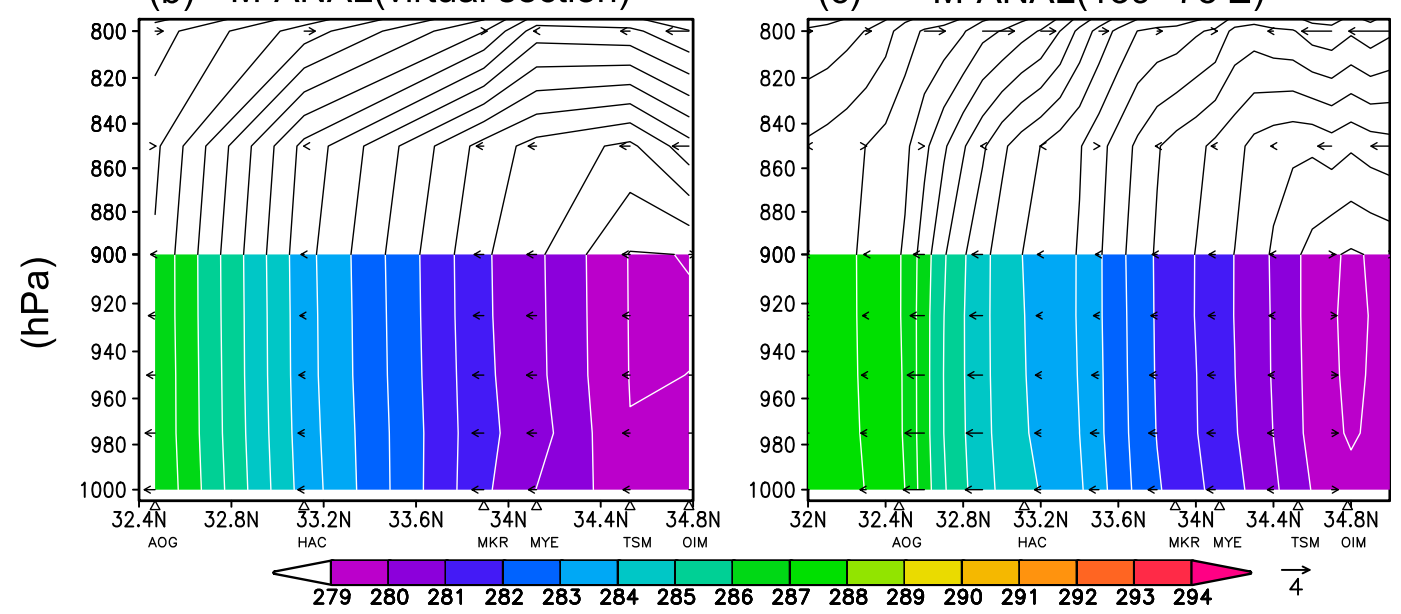

FIG. 12. (a) Meridional cross sections of $\theta$ (1-K interval) on day A based on (a) the TIS observations and (b),(c) M-ANAL data. (b) The virtual cross section is based on six vertical profiles collected at the nearest grid point to the airports used for the TIS observations. (c) The conventional cross section is based on all the gridpoint values in the M-ANAL data.

sampling, the frequent vertical sampling enables us to depict richer structures in the MABL with our observations than with the M-ANAL data (Figs. $12 \mathrm{~b}$ and 12c). The observed cross section displays a nearly vertical uniform layer in $\theta$ up to $940 \mathrm{hPa}$ in the southern portion at AOG and $\mathrm{HAC}\left(32.4^{\circ}-33.2^{\circ} \mathrm{N}\right)$, indicating the development of the mixed layer in the MABL, apparently induced by active heat release from the ocean surface. In contrast, a low $\theta$ intrusion from the north at the $980-\mathrm{hPa}$ level is distinct in the northern portion, at MKR, MYE, TSM, and OIM $\left(33.8^{\circ}-34.8^{\circ} \mathrm{N}\right)$, forming an unstable surface layer below the intrusion and a strong nearsurface inversion layer above it. While these types of cold-air outbreaks are generally characterized by a deep mixed layer in the M-ANAL cross sections, our observations show a less-mixed vertical profile in the nearsurface layers. The low $\theta$ intrusion at around the $980-\mathrm{hPa}$ level is still seen in the vertical profiles of subsequent supplemental flight legs at OIM (flight S1 at 1228 JST and flight S3 at 1339 JST) and TSM (flight S2 at 1242 JST) on day A (Fig. 14), showing that the intrusion in the northern portion of the meridional section may remain for at least a few hours. This low $\theta$ is also seen in the afternoon scheduled flight legs at MYE (flight 32 at 1511 JST) and MKR (flight 22 at 1524 JST) on day A (not shown here). While the IR image on day A (Fig. 6c) shows clouds in the observation area, the observed relative humidity is no more than $65 \%$ in the meridional cross section (not shown here). This suggests that the cloud base is much higher than the upper limit of the observed profiles.

The overall MABL structure in the M-ANAL data tends to be very simple to reproduce the observed variations. While the absolute values of $\theta$ in the virtual cross section are close to those observed at the individual airports (Fig. 12b), a vertically uniform layer of $\theta$ in the M-ANAL data dominates up to the 850 -hPa level throughout the cross section, indicating a considerable overestimation of the vertical mixing in the numerical model used for the assimilation. It may be suggested that the discrepancy between the TIS observations and the M-ANAL data is derived from the reduced spatial and temporal representativeness of the observed profiles, which may occasionally suffer some land effects over the islands. However, this is unlikely to be the case because the observed profiles display the coherent structure of the low $\theta$ intrusion over the northern four airports. In contrast, the mixed layer in the M-ANAL profiles is thickly developed in all the individual single cross sections, in both the neighboring longitudes and assimilated 
(a)

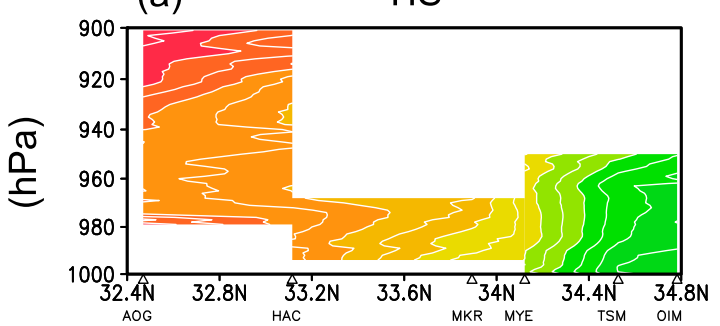

(b) M-ANAL(virtual section)

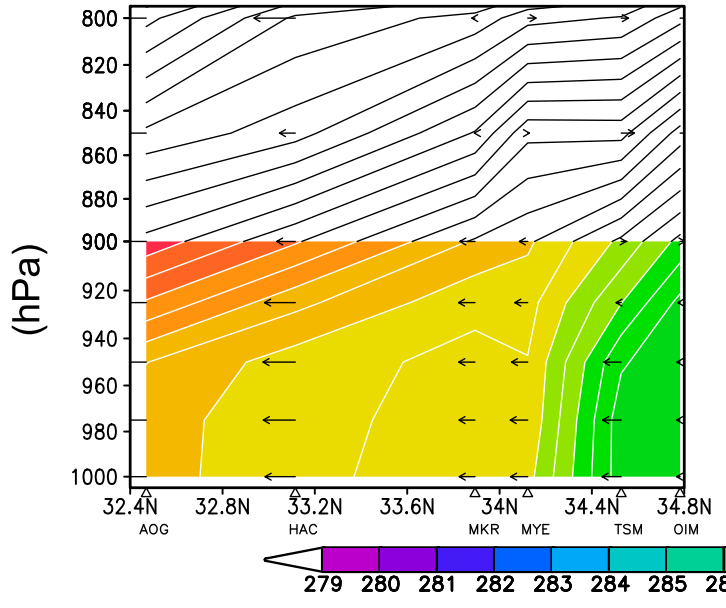

(c) M-ANAL $\left(139^{\circ} 75^{\prime} \mathrm{E}\right)$

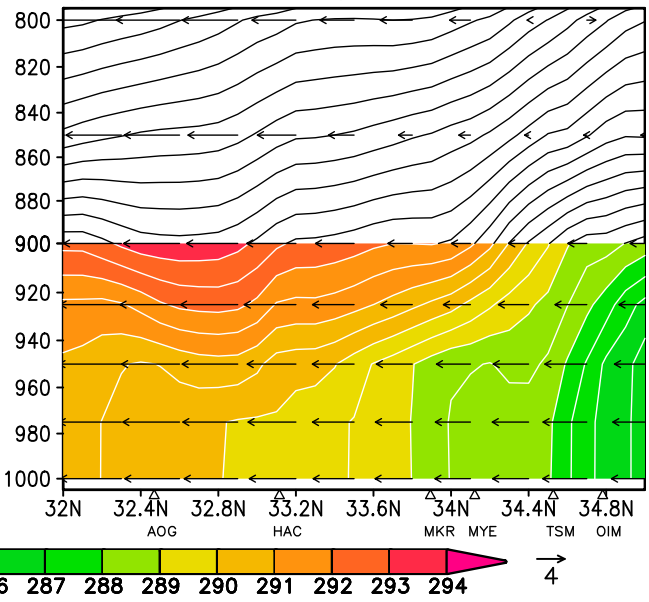

FIG. 13. As in Fig. 12, but on day B.

time steps and the virtual cross sections. It is therefore assumed that the oversized vertical mixing in the numerical model used for the assimilation acts to mask any finer vertical structures, such as the observed low $\theta$ intrusion near the surface layer. Although the main inversion at the top of the mixed layer over OIM occurs at the 880 -hPa level in the M-ANAL profiles, which is $20 \mathrm{hPa}$ lower than over the other points in the southern portion, the near-surface inversion at OIM is observed at a much lower level, that is, at $980 \mathrm{hPa}$.

The observed cross section on day B (Fig. 13a) also displays meridional changes in the MABL, with a mixed-layer development up to the $950-\mathrm{hPa}$ level at the northern three airports, and a high $\theta$ layer at the 980$\mathrm{hPa}$ level at the southern three airports. Consequently, the inversion height shows a southward decrease from the 950-hPa level at OIM to the near-surface at AOG. The assimilated cross sections on day B (Figs. 13b and 13c) are partly successful in reproducing these observed features, including the gradual southward decrease of the inversion height and the weak inversion at the 980$\mathrm{hPa}$ level at the northern three airports. Despite this overall agreement of the inversion heights, the cross sections of the MABL structure fail to represent the observed fine structures, such as the high $\theta$ layer in the southern portion. Furthermore, the intensity of the inversion at the $950-\mathrm{hPa}$ level in the northern portion is weaker in the M-ANAL profiles than in the observations. This discrepancy is probably attributed to the oversized mixing of the MABL, as discussed for day A. Although we here showed only two examples of the meridional cross sections, from day $\mathrm{A}$ and day $\mathrm{B}$, the discrepancies in the M-ANAL data are found over the entire period of our observations. Here we have made an intercomparison of the time-latitude sections of $\Delta \theta$ between the observations and the M-ANAL data (Fig. 15), and have shown that the M-ANAL data fails to reproduce the observed meridional modulations of the synoptic fluctuations in $\Delta \theta$.

\section{d. Intercomparison of the vertical profiles with GPS sonde soundings}

To validate our observed vertical profiles, we conducted GPS sonde soundings near the HAC airport for 2 days, on 15 and 16 March 2011. ${ }^{1}$ Our sounding site is close to the runway of HAC, at only 2-km distance. The

\footnotetext{
${ }^{1}$ We originally planned to perform the soundings for a week. However, the logistics for the observations became compromised as a result of the disaster following the Tohoku-Pacific Ocean earthquake and tsunami.
} 


\section{Day A (25 Dec 2010)}

(a) TSM

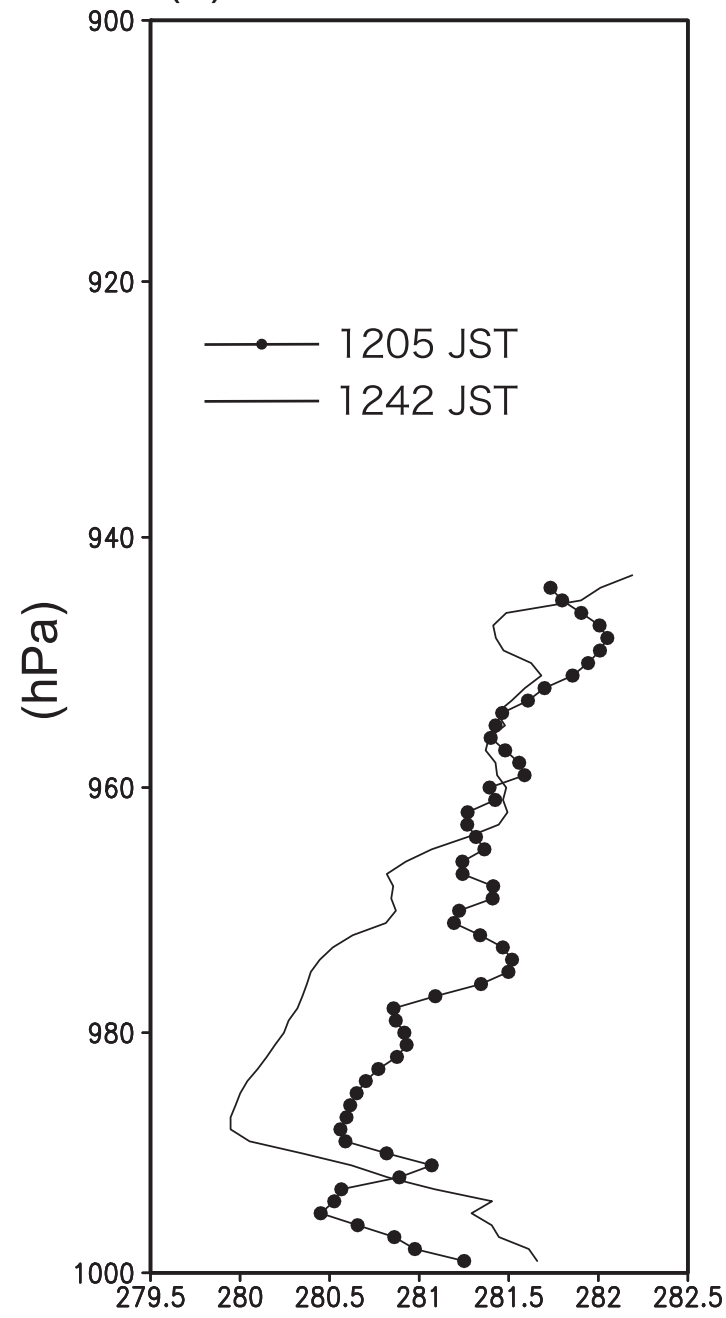

(b) OIM

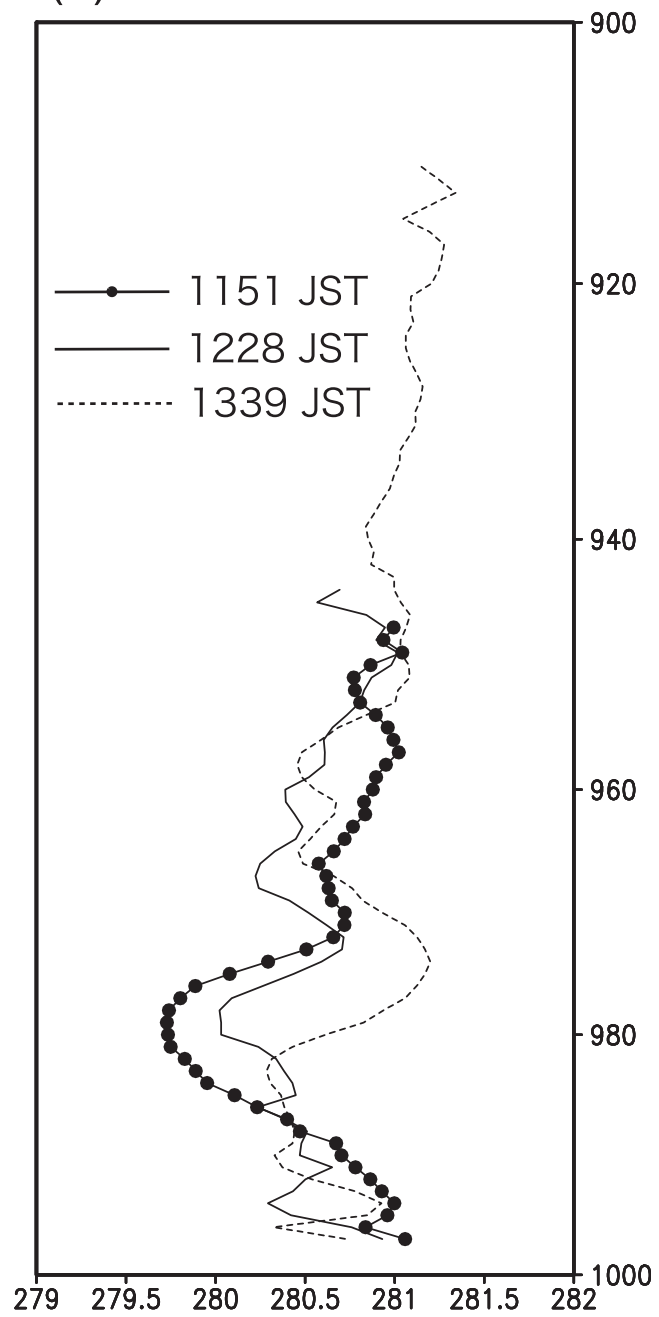

FIG. 14. Individual observed vertical profiles of $\theta(\mathrm{K})$ at (a) TSM and (b) OIM on day A. The profiles with solid lines and closed circles are employed in the observed vertical cross section in Fig. 12. Profiles with solid lines and dashed lines are from observations during the ascents of other flight legs on the same day. The departure time (JST) of the ascent is indicated for each of the profiles.

site is on the cliff edge, at an altitude of $15 \mathrm{~m}$, facing the sea to obtain the profiles with the sea surface as the bottom. While the JMA launches sondes every $12 \mathrm{~h}$ (0830 and 2030 JST) from its own sounding station, $2.5 \mathrm{~km}$ from our sounding site, the altitude of the station at the foot of the island mountain is $151 \mathrm{~m}, 49 \mathrm{~m}$ higher than the HAC airport (Table 1). Therefore, only our additional soundings allow us to determine whether the observational system on the TIS can provide useful vertical profiles, including the lowest $50 \mathrm{~m}$.

In the morning on day B (Fig. 16), the TIS service provided two ascending profiles at 0923 (black curve) and 1034 JST (red curve), and one descending profile at
1008 JST (blue curve). The vertical profile at 1034 JST was used in Figs. 8a and 13a. Although the time difference between the three TIS observations is around $1 \mathrm{~h}$, the profiles observed by the TIS service show a striking resemblance, specifically with respect to the lapse rate up to $900 \mathrm{hPa}$. The differences in measured temperature are smaller than $1^{\circ} \mathrm{C}$ between the three profiles. Before this initiative was implemented, we imagined that artificial vertical mixing due to the helicopter rotor might affect the vertical profile of the TIS observations. However, this similarity of the profiles indicates that each profile is accurate, regardless of whether it was collected during ascent or descent. 
(a)
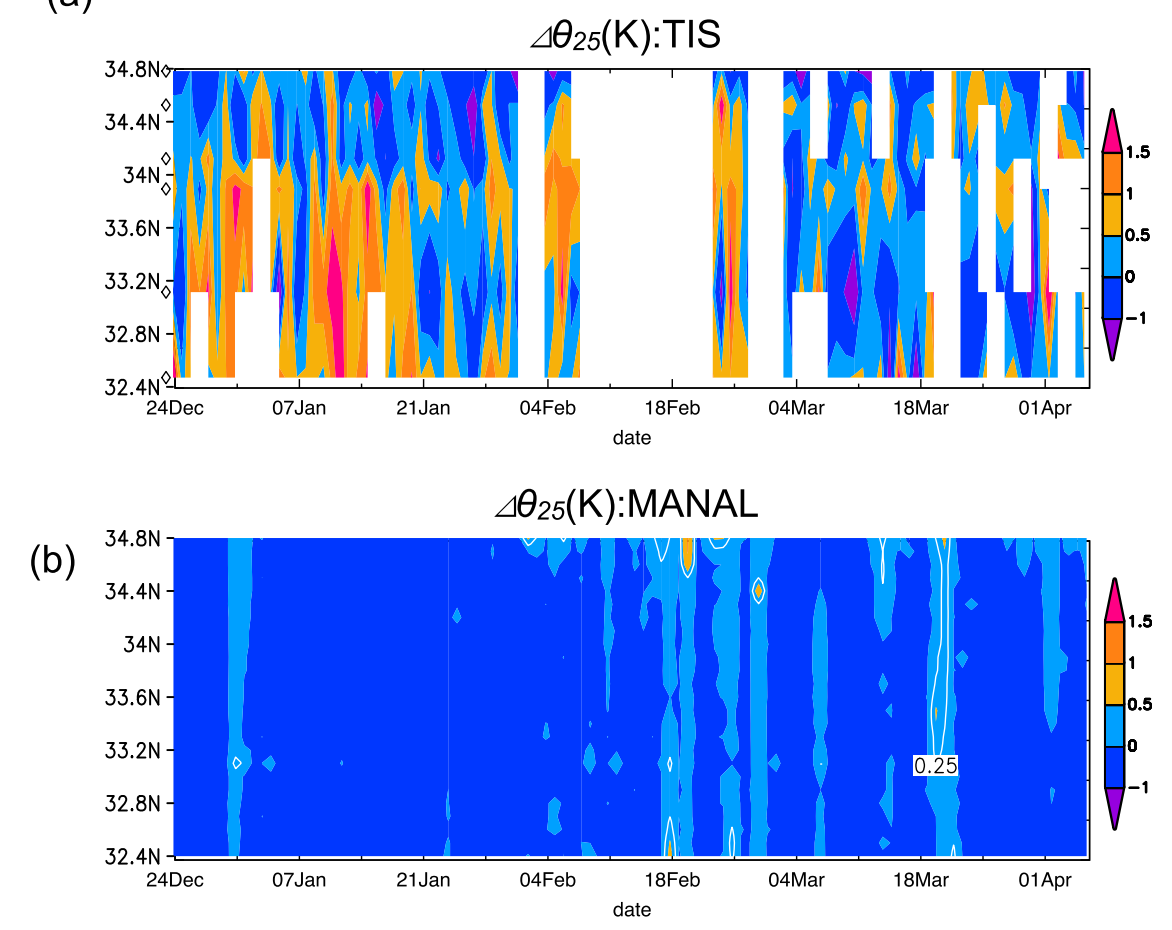

FIG. 15. Latitude-time section of $\Delta \theta_{25}$ (K) based on (a) the TIS observations and (b) the M-ANAL data. Coloring convention is shown to the right of the panels.

While distinct departures are found between the profiles in the near-surface layer, these differences are apparently due to natural temperature variations in the near-surface layer as opposed to measurement errors, because the surface temperatures from the AMeDAS record at the HAC airport at the departure times also show comparable fluctuations $\left(\sim 1^{\circ} \mathrm{C}\right)$. In fact, in the 10-min-interval AMeDAS record from day $\mathrm{B}$, the surface temperature fluctuates from $17.0^{\circ}$ to $18.5^{\circ} \mathrm{C}$ during 0920 1040 JST, while the differences in the surface temperature observed by the TIS service and AMeDAS are no more than $0.9^{\circ} \mathrm{C}$. These small differences between the TIS and AMeDAS measurements are also found in the daily observations, as shown in Fig. 8b (blue and black curves).

We compare the three vertical temperature profiles observed by the TIS service on day B to those from the GPS soundings launched by ourselves (solid gray curve) and the JMA (dashed gray curve) on the same day (Fig. 16). Although the JMA's sounding was launched from a mountain slope at the 991.4-hPa level, the vertical temperature profile above the 965 -hPa level is close to those observed by the TIS. A relatively large departure of temperature in the sounding profile from the TIS profiles occurs in a layer from 965 to $991 \mathrm{hPa}$, probably due to some land effects along the mountain slope. While our sounding is in fairly good agreement above the 940-hPa level, the comparison shows large temperature differences, nearly $2^{\circ} \mathrm{C}$ lower in the sounding profile than in the TIS profiles, that is, below $940 \mathrm{hPa}$. We speculate that these large differences are because the TIS and sonde observed different native temperature profiles, rather than experiencing observation errors. The TIS flights attempt to navigate the ocean as quickly as possible after departures to avoid turbulence over the small islands, although the exact position of the helicopter is not recorded. In contrast, the position record of our sounding on day B shows that the sonde moved upward along the slope of Mount Miharayama, whose summit is at $701 \mathrm{~m}$ (930-940-hPa level). These facts indicate that while the TIS service observed the temperature profile over the ocean, our soundings instead captured the profile along the slope below the mountain summit. It is interesting to note that the two sounding profiles are more similar above $940 \mathrm{hPa}$, indicating reduced land effects above the mountain summit.

As on day $\mathrm{B}$, we conducted a sounding at the same location one day after day B, while TIS service recorded three temperature profiles during 0917-1025 JST. As on day $\mathrm{B}$, the temperature in the sounding profiles is around $2^{\circ} \mathrm{C}$ lower than that in the three TIS profiles (not shown here). 


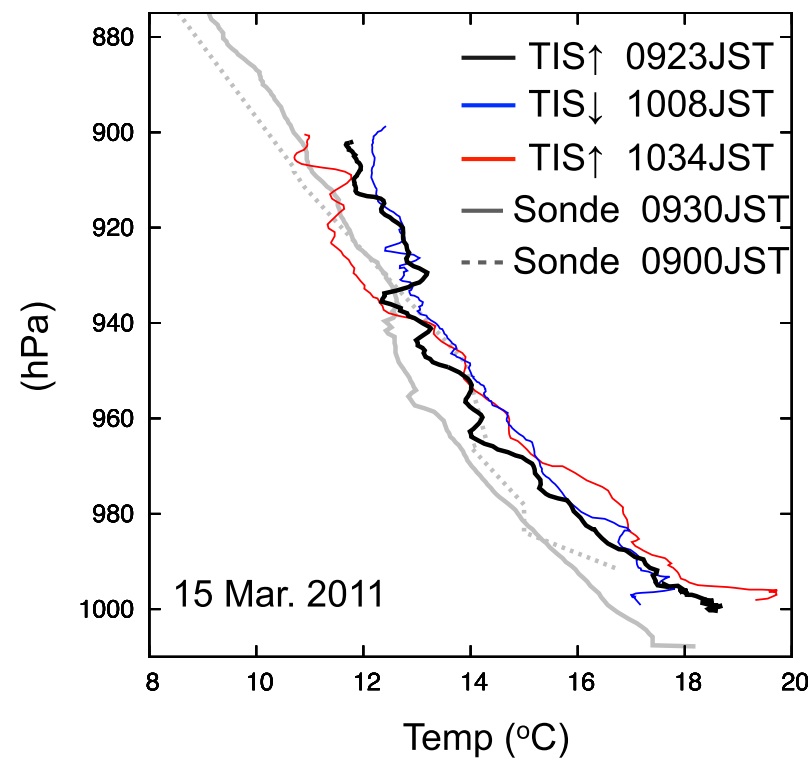

FIG. 16. Vertical temperature profiles $\left({ }^{\circ} \mathrm{C}\right)$ from the TIS observations (black, blue, and red curves) and GPS soundings (solid and dashed gray curves) on day B at HAC. The observation time (JST) is indicated to the right of the lines.

\section{e. Dynamic pressure effect on temperature}

It may be proposed that the thermocouples of our observation system suffered from dynamic pressure in the high-speed helicopter fleet. Total pressure $P$ on the moving fleet with speed $v$ is $P=p+(1 / 2) \rho v^{2}$, where $p$ and $\rho$ are the static pressure and the density of air, respectively. Assuming an adiabatic condition, we see the following relationship between the observed temperature $T_{\mathrm{obs}}$ and real air temperature $T_{\text {real }}$ :

$$
T_{\text {real }}=T_{\text {obs }}\left(\frac{p}{P}\right)^{\gamma-1 / \gamma},
$$

where $\gamma$ is the ratio of specific heat for a constant pressure to the specific heat for a constant volume. Under the optimal operational speed (around $40 \mathrm{~m} \mathrm{~s}^{-1}$ ) for the ascent of the TIS fleet, the dynamic pressure is estimated to be $10 \mathrm{hPa}$. Therefore, the dynamic pressure effect on the observed temperature is no more than $1^{\circ} \mathrm{C}$ in the observed temperature range of $2^{\circ}-20^{\circ} \mathrm{C}$. This estimation indicates that the dynamic pressure effect alone cannot explain the observed temperature differences between the results from the TIS service and the sonde soundings. However, additional soundings near the TIS area of ascent and total pressure observations from the helicopters are necessary to identify and estimate any systematic errors; such tasks should be the focus of future study.

\section{Summary}

We developed a new observation system for use on a helicopter shuttle connecting the six Izu islands off Japan to obtain frequent records of the vertical temperature and moisture profiles of the MABL across the SST front along the Kuroshio, where the in situ measurement of the MABL has been limited. Through cooperation with the air service company, the observation was mostly successful for a 3-month period from 24 December 2011 to 6 April 2011, although an accidental power failure meant measurements were not made for 14 days during 9-22 February 2011. Self-made thermocouples, the Vaisala Inc. HUMICAP 180, and the OMEGA Engineering Inc. PX2760-600A5V were used to measure temperature, moisture, and pressure records, respectively, at a $1-\mathrm{Hz}$ sampling rate. These provided vertical profiles of those variables from the surface up to nearly $900 \mathrm{hPa}$ with a high vertical resolution of no more than $10 \mathrm{~m}$, during helicopter ascent and descent near the islands as a part of the daily TIS service. With 24 AAA-type battery (100 Wh), 3 months of continuous observation was possible, facilitated by the powersaving control of the observation system by the CR1000-4M logging device from Campbell Scientific, Inc. The observation system was thus developed to meet flight regulations.

To validate the daily vertical profiles obtained using our system, we made several intercomparisons with datasets provided by the JMA. We employed only those profiles obtained during ascent because the profile during descent sometimes contained spikes of noise. Moreover, the descending speed was not as constant as the ascending one. Synoptic time-scale fluctuations are pronounced in the observed vertical profiles above the HAC airport, whose surface variables are significantly correlated with those of the weather station on the HAC airport and with those of the M-ANAL at the nearest grid point. This indicates the reliability of our observations, at least in the near-surface layer. While a richer MABL structure, including a cold-air intrusion and a strong near-surface inversion, is found in temporal and meridional sections based on the vertically high-resolution observed profiles, the vertical difference in potential temperature $(\Delta \theta)$ in the M-ANAL data is nearly nonexistent for most of the observation period, and it is therefore unsuccessful in reproducing the observed MABL structure. This is probably due to the oversized mixing component in the numerical model used for the assimilation.

Another intercomparison was made between the observations and the vertical profiles of atmospheric soundings conducted by the JMA and ourselves. While 
relatively large temperature differences $\left(\sim 2^{\circ} \mathrm{C}\right)$ were observed between the TIS observations and the soundings in the near-surface layer below $940 \mathrm{hPa}$, all of the profiles above $940 \mathrm{hPa}$ are in agreement with one another. The discrepancy between the near-surface layer profiles may be due to the fact that our sounding was made along the slope of the island mountain, while the helicopter fleet tends to ascend over the ocean. Soundings at an offshore location should be preferred for further validations. However, the correspondence of the profiles in the upper MABL above $940 \mathrm{hPa}$ strongly suggests that any systematic errors in the temperature measurements from our observation system, caused by dynamic pressure from the fast-moving helicopter, are negligible. Moreover, artificial mixing by the helicopter rotor is also assumed to be negligible, as indicated by the similarity of vertical profiles from ascents and descents.

The results of the validation work of the present study provide us confidence in being able to capture the synoptic time-scale fluctuations of the MABL over the Kuroshio region. Since previous observational studies of the MABL across the KE SST front during winter (Tokinaga et al. 2006, 2009) have been based on a single transect or climatological meridional transect, the synoptic weather condition on those transects was dominated by monsoonal northerlies, inducing relatively cool air to flow over a warmer sea surface. Given future longer-period TIS observations, we will be able to examine the spatial transitions of the MABL across the SST front and their modulations under the cold and dry northerlies and warm and moist southerlies. Such an investigation has been conducted by Pezzi et al. (2009) based on the multiyear measurements of the MABL in the Brazil-Malvinas Confluence region. On a basis of the longer-period TIS observation, it will be interesting and challenging to properly model cases of stable stratification for better numerical weather prediction (NWP). While weather reports from commercial aircrafts have been an important data source for NWP, such reports at the planetary boundary are very limited and are only near to the major hub airports (Moninger et al. 2003). The numerical experiment by de Camargo et al. (2013) was successful in reproducing the observed structure of the MABL over the Brazil-Malvinas Confluence region by assimilating radiosonde data with high-resolution SST data. This motivates us to conduct an additional similar assimilating experiment with our TIS observations. This will additionally help to assess the usefulness of our MABL observations for NWP.

Acknowledgments. We thank Mr. N. Naito, Mr. T. Miyauchi, Mr. T. Asakura, and Mr. T. Namiki of Toho Air Service Co., Ltd., for helping and supporting our observation on Tokyo Island Shuttle. Tokyo Metropolitan Islands Promotion Corporation has approved our observational initiative. Practical advice from Mr. K. Shinbori and Mr. S. Nakatsubo, and the other members in the Technical Division of the Institute of Low Temperature Science, Hokkaido University, were helpful in developing the observation system. This study was supported partially by Grants-In-Aid for Scientific Research by the Ministry of Education, Culture, Sports, Science and Technology of Japan (22340132, 22106007, and 26241003).

\section{REFERENCES}

Adachi, S., and F. Kimura, 2007: A 36-year climatology of surface cyclogenesis in East Asia using high-resolution reanalysis data. SOLA, 3, 113-116, doi:10.2151/sola.2007-029.

de Camargo, R., E. Todesco, L. P. Pezzi, and R. Buss de Souza, 2013: Modulation mechanisms of marine atmospheric boundary layer at the Brazil-Malvinas Confluence region. J. Geophys. Res. Atmos., 118, 6266-6280, doi:10.1002/jgrd.50492.

Hayes, S. P., M. J. McPhaden, and J. M. Wallace, 1989: The influence of sea-surface temperature on surface wind in the eastern equatorial Pacific: Weekly to monthly variability. J. Climate, 2, 1500-1506, doi:10.1175/1520-0442(1989)002<1500: TIOSST>2.0.CO;2.

Iizuka, S., 2010: Simulations of wintertime precipitation in the vicinity of Japan: Sensitivity to fine-scale distributions of sea surface temperature. J. Geophys. Res., 115, D10107, doi:10.1029/2009JD012576.

Kawamura, H., H. Qin, F. Sakaida, and R. Setiawan, 2010: Hourly sea surface temperature retrieval using the Japanese geostationary satellite, Multi-functional Transport Satellite (MTSAT). J. Oceanogr., 66, 61-70, doi:10.1007/s10872-010-0005-0.

Kwon, Y.-O., M. A. Alexander, N. A. Bond, C. Frankignoul, H. Nakamura, B. Qiu, and L. A. Thompson, 2010: Role of the Gulf Stream and Kuroshio-Oyashio systems in large-scale atmosphere-ocean interaction: A review. J. Climate, 23, 32493281, doi:10.1175/2010JCLI3343.1.

Lindzen, R. S., and S. Nigam, 1987: On the role of sea surface temperature gradients in forcing low-level winds and convergence in the tropics. J. Atmos. Sci., 44, 2418-2436, doi:10.1175/ 1520-0469(1987)044<2418:OTROSS>2.0.CO;2.

Moninger, W. R., R. D. Mamrosh, and P. M. Pauley, 2003: Automated meteorological reports from commercial aircraft. Bull. Amer. Meteor. Soc., 84, 203-216, doi:10.1175/BAMS-84-2-203.

Nakamura, H., A. Nishina, and S. Minobe, 2012: Response of storm tracks to bimodal Kuroshio path states south of Japan. J. Climate, 25, 7772-7779, doi:10.1175/JCLI-D-12-00326.1.

Ninomiya, K., 1977: Heat energy budget of the polar air-mass transformed over Kuroshio region under the situation of strong subsidence. J. Meteor. Soc. Japan, 55, 431-441.

Pezzi, L. P., R. B. Souza, M. S. Dourado, C. A. E. Garcia, M. M. Mata, and M. A. F. Silva-Dias, 2005: Ocean-atmosphere in situ observations at the Brazil-Malvinas Confluence region. Geophys. Res. Lett., 32, L22603, doi:10.1029/2005GL023866.

_, R. B. de Souza, O. Acevedo, I. Wainer, M. M. Mata, C. A. E. Garcia, and R. de Camargo, 2009: Multiyear measurements of the oceanic and atmospheric boundary layers at the BrazilMalvinas confluence region. J. Geophys. Res., 114, D19103, doi:10.1029/2008JD011379. 
Small, R. J., and Coauthors, 2008: Air-sea interaction over ocean fronts and eddies. Dyn. Atmos. Oceans, 45, 274-319, doi:10.1016/j.dynatmoce.2008.01.001.

Song, Q., D. B. Chelton, S. K. Esbensen, N. Thum, and L. W. O'Neill, 2009: Coupling between sea surface temperature and low-level winds in mesoscale numerical models. J. Climate, 22, 146-164, doi:10.1175/2008JCLI2488.1.

Sweet, W., R. Fett, J. Kerling, and P. La Violette, 1981: Air-sea interaction effects in the lower troposphere across the north wall of the Gulf Stream. Mon. Wea. Rev., 109, 1042-1052, doi:10.1175/1520-0493(1981)109<1042:ASIEIT>2.0.CO;2.

Tanimoto, Y., S.-P. Xie, K. Kai, H. Okajima, H. Tokinaga, T. Murayama, M. Nonaka, and H. Nakamura, 2009: Observations of marine atmospheric boundary layer transitions across the summer Kuroshio Extension. J. Climate, 22, 1360 1374, doi:10.1175/2008JCLI2420.1.
—, T. Kanenari, H. Tokinaga, and S.-P. Xie, 2011: Sea level pressure minimum along the Kuroshio and its extension. J. Climate, 24, 4419-4434, doi:10.1175/2011JCLI4062.1.

Tokinaga, H., and Coauthors, 2006: Atmospheric sounding over the winter Kuroshio Extension: Effect of surface stability on atmospheric boundary layer structure. Geophys. Res. Lett., 33, L04703, doi:10.1029/2005GL025102.

_ Y Y. Tanimoto, S.-P. Xie, T. Sampe, H. Tomita, and H. Ichikawa, 2009: Ocean frontal effects on the vertical development of clouds over the western North Pacific: In situ and satellite observations. J. Climate, 22, 4241-4260, doi:10.1175/2009JCLI2763.1.

Wallace, J. M., T. P. Mitchell, and C. Deser, 1989: The influence of sea-surface temperature on surface wind in the eastern equatorial Pacific: Seasonal and interannual variability. J. Climate, 2, 1492-1499, doi:10.1175/1520-0442(1989)002<1492: TIOSST>2.0.CO;2. 